\title{
Apparent permeability prediction of organic shale with generalized lattice Boltzmann model considering surface diffusion effect
}

\author{
Junjian Wang ${ }^{\mathrm{a}, \mathrm{b}}$, Li Chen ${ }^{\mathrm{c}, \mathrm{b}}$, Qinjun Kang ${ }^{\mathrm{b}, *}$, Sheik S Rahman ${ }^{\mathrm{a}}$ \\ ${ }^{a}$ School of Petroleum Engineering, University of New South Wales, Sydney, \\ NSW,Australia,2033 \\ ${ }^{b}$ Earth and Environmental Sciences Division, Los Alamos National Laboratory, Los \\ Alamos, NM, USA,87545 \\ ${ }^{c}$ Key Laboratory of Thermo-Fluid Science and Engineering of MOE, School of Energy \\ and Power Engineering, Xi'an Jiaotong University, Xi'an, Shanxi, China, 710049
}

\begin{abstract}
Gas flow in shale is associated with both organic matter (OM) and inorganic matter (IOM) which contain nano-pores ranging in size from a few to hundreds of nano-meters. In addition to the non-continuum effect which leads to an apparent permeability of gas higher than the intrinsic permeability, the surface diffusion of adsorbed gas in organic pores also can influence the apparent permeability through its own transport mechanism. In this study, a generalized lattice Boltzmann model (GLBM) is employed for gas flow through the reconstructed shale matrix consisting of OM and IOM. The Expectation-Maximization (EM) algorithm is used to assign the pore size distribution to each component, and the dusty gas model (DGM) and generalized Maxwell-Stefan model (GMS) are adopted to calculate the apparent permeability accounting for multiple transport mechanisms including viscous flow, Knudsen diffusion and surface diffusion. Effects of pore radius and pressure on permeability of both IOM and OM as well as effects of Langmuir parameters on OM are investigated. The effect of total organic content and distribution on the apparent permeability of the reconstructed shale matrix at different surface diffusivity is also studied. It is found that the influence
\end{abstract}

${ }^{*}$ Corresponding author at: Earth and Environmental Sciences Division, LANL, Los Alamos, NM 87545

Email address: qkang@lanl.gov (Qinjun Kang)

Preprint submitted to Fuel

May 3, 2016

(C) 2016. This manuscript version is made available under the Elsevier user license http://www.elsevier.com/open-access/userlicense/1.0/ 
of pore size and pressure on the apparent permeability of organic matter is affected by the surface diffusion of adsorbed gas. Moreover, surface diffusion plays a significant role in determining apparent permeability and the velocity distribution of shale matrix.

Keywords: shale gas, lattice Boltzmann method, surface diffusion

\section{Introduction}

Shale gas reservoirs contain a significant proportion of hydrocarbon energy, and the successful exploitation of such resource plays an increasingly important role in meeting world's demand for natural gas. Organic shale is known to be fine grained sedimentary rocks consisting of inorganic matter (IOM) and organic matter $(\mathrm{OM})$ with pore sizes ranging from nanoto meso- scale[1]2, in each component of which are involved different flow mechanisms 3 . In the literature, gas flow on nano- to micro-scale in shale is often referred to as rarefied gas flow [4], where the mean free path of gas is comparable to the characteristic length of the micro-pores or throats. Gas flow in shale matrix usually leads to a deviation from the continuum theory [5]. Moreover, previous studies have confirmed that the amount of adsorbed gas constitutes about $20 \%-80 \%$ of the total gas in place of shale gas reservoir [6] [7] [8, and the surface diffusion of adsorbed gas is an important transport mechanism in these reservoirs [9] [10]. A physics-based understanding of gas transport mechanism in shale including non-continuum behaviours and surface diffusion is essential for the development of accurate descriptive transport simulators to predict fluid flow and transport in shale.

For decades, the problem of modelling gas transport in narrow pores and confined spaces in shale has attracted considerable attention among petroleum engineers. Generally speaking, two approaches have been proposed to describe the gas transport and to calculate apparent permeability of organic shale. The first approach is to modify the non-slip boundaries in continuum model by accounting for slip boundary conditions. Beskok and Karniadaki[11] derived a unified Hagen-Poiseuille-type formula to take account of slip flow, transition flow and free molecular flow. Later, Civan[12] and Florence et al. [13] proposed different forms of rarefaction coefficient in Beskok-Karniadaki model. Xiong et al.[14] introduced a capillary model by adding the mass transfer of adsorbed gas into Beskok-Karniadaki empirical equation to study the impact of the adsorbed gas and surface diffusion on 
gas apparent permeability. The second approach is the superposition of various transport mechanisms. Javadpour [3] combined slip flow and Knudsen diffusion into gas flux equation and derived an equation for apparent permeability. Freeman et al.[15] applied dusty gas model (DGM) to account for Knudsen diffusion in shale gas reservoir. Singh et al.4] combined viscous flow with Knudsen diffusion in their non-empirical apparent permeability model(NAP), and validated the model with previous experimental data. The results show that the NAP can be used for Kn less than unity. Wu et al. [9] further proposed two weighted factors for viscous flow and Knudsen diffusion, respectively. The surface diffusion was also considered in their apparent permeability model.

The limitation of the application of analytical or semi-analytical models to gas flow in porous media is that the pore structure is usually relatively simple, such as capillaries 3] 4] [14. Such simplification might produce erroneous results because the pore structures in shale are very complex, as detected by well-established characterization techniques such as SEM[1] [16]. To improve this, different pore-scale models have been proposed to link the micro-structure of the porous media with fluid flow characteristics. Among them, the lattice Boltzmann (LB) method has gone through significant improvements over the past years and has become a viable and efficient substitute for conventional N-S solvers in many flow problems especially porous flow and multiphase flow[17]. Because of its inherent kinetic nature, the LB method has attracted huge interest in its extension to simulating microgaseous flows, and tremendous efforts have been made to advance the LBM since 2002 18] 19 20. With the implementation of appropriate slip boundary conditions and/or effective relaxation time, the LBM was successfully extended for simulation of gaseous flows in slip flow and transition flow regimes, and these LBM approaches have been applied to study gas transport in shale gas reservoir 21] 222 [23]. However, because of the complexity of boundary conditions, most of the applications of the slip-based LBM are limited to single channel or bundle of channels 23]. Recently, Chen et al.20]24] proposed a LB model based on the Dusty gas model (DGM) to predict the apparent permeability of shales with complex porous structures, where the complexity of the slip boundary conditions are avoided. Very recently, Chen et al. [25] improved the generalized lattice Boltzmann model (GLBM) proposed by Guo and Zhao[26] for fluid flow through porous media by including the Klinkenberg effect, and performed several simulations based on heterogeneous shale matrix with natural fractures, organic matter and inorganic minerals 25] 27. 
In this study, we present a novel adaptation of the GLBM with slip effect proposed by Guo and Zhao[26] and Chen et al. 25] for micro-gas flow in 2-dimensional (2-D) porous shale with surface diffusion further considered. The novelty of the present study is the use of the DGM-generalized Maxwell-Stefan (GMS) approach to calculate the local permeability taking the adsorbed gas and surface diffusion into account. The rest of the paper is as follows. The mathematical and numerical models for predicting apparent permeability of organic shale is introduced in Section 2, and the validation of numerical models is also shown in this section. In section 3 , firstly the permeability of IOM and OM are discussed, and then the effects of component distribution and organic content on apparent permeability of reconstructed shale sample are analyzed. Finally, some conclusions are drawn in section 4.

\section{Model description}

\subsection{Dusty gas model and generalized Maxwell-Stefan model}

The transport of non-adsorbable gas through porous media is in general caused by concentration or pressure gradients. It has been confirmed experimentally and mathematically that the corresponding fluxes can be calculated with high accuracy using the DGM or Knudsen-like theory[28]. However, most recent studies indicate that the above applications have failed to model the gas transport in the presence of the adsorbed gas[29]. To take account of the adsorbed gas effect, Krishna and co-workers 30] 31] extended the Maxwell-Stefan formulation in the spirit of the DGM by introducing a generalized Maxwell-Stefan model (GMS) for surface diffusion of adsorbed gas(See Fig. 1). With the premise that the DGM appropriately describes the transport in the "quasi-bulk" phase located in the pore space whereas the GMS describes gas molecular transport at the surface, the total molar flux is expressed by:

$$
N_{\text {total }}=N_{D G M}+N_{G M S},
$$

where $N_{D G M}$ is the contribution to the flux from the DGM $\left(\mathrm{mol} \cdot \mathrm{m}^{-2} \cdot \mathrm{s}^{-1}\right)$, in which adsorption and surface diffusion is ignored, and $N_{G M S}$ is the contribution from the GMS for surface diffusion $\left(\mathrm{mol} \cdot \mathrm{m}^{-2} \cdot \mathrm{s}^{-1}\right)$. Detailed descriptions of DGM and GMS are given in the next two subsections, respectively. 


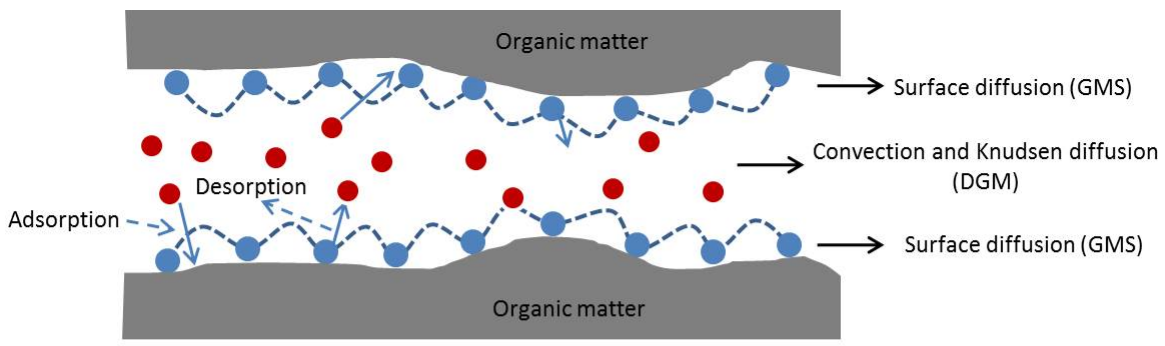

(a)

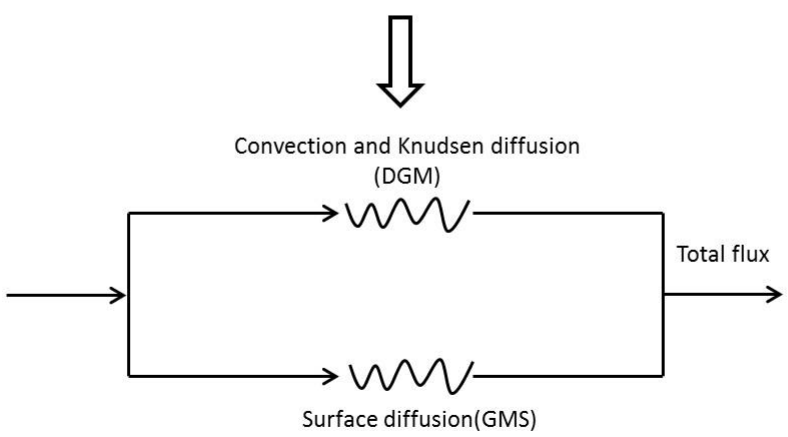

(b)

Figure 1: Schematic diagram of gas transport in organic pores of shale matrix based on DGM-GMS model proposed by Krishna and co-workers 30 31 (a) Gas transport mechanisms in organic pores (b) Conceptual models for different gas transport

\subsubsection{Dusty gas model}

The DGM is based on the combination of the Maxwell-Stefan diffusion equations and the characteristics of mass transfer in porous media. The basic idea of DGM is to consider the solid as a dummy species of infinite mass, which is constrained by unspecified external forces and has zero drift velocity. For a single species $i$ in a n-component mixture the following flux equation of the DGM holds[32]:

$$
-\frac{P}{R T} \nabla x_{i}-\frac{x_{i}}{R T}\left(1+\frac{K_{0}}{\eta D_{K, i}} P\right) \nabla P=\sum_{j=1, j \neq i}^{n} \frac{x_{j} N_{i}-x_{i} N_{j}}{\varepsilon / \tau D_{i j}^{0}}+\frac{N_{i}}{D_{K, i}},
$$

where $P$ is pressure $\left(P_{a}\right), R$ is the universal gas constant $\left(8.314 \mathrm{~J} \cdot \mathrm{K}^{-1} \cdot \mathrm{mol}^{-1}\right)$, $T$ is temperature $(K), \eta$ is dynamic viscosity $\left(k g \cdot \mathrm{m}^{-1} \cdot \mathrm{s}^{-1}\right), x_{i}$ is the molar fraction of species $i, D_{i j}^{0}$ is the binary molecular diffusivity in gas phase $\left(\mathrm{m}^{2} / \mathrm{s}\right)$, and $\varepsilon / \tau$ is the ratio of porosity to tortuosity. The Knudsen diffusivity 
111

$D_{k, i}$ of species $i$ is defined as:

$$
D_{K, i}=\frac{4}{3} K_{c} \sqrt{\frac{8 R T}{\pi M_{i}}}
$$

where $M_{i}$ is the Molecular weight of species $i(\mathrm{~kg} / \mathrm{mol})$. In the case where the pore space is assumed to have a diameter $d_{p}(m)$, the values of Knudsen coefficient, $K_{c}$ and the permeability of the porous medium quantifying the viscous flux, $K_{0}$ can be related as 33 :

$$
K_{c}=\frac{8}{d_{p}} K_{0}=\frac{\varepsilon}{\tau} \frac{d_{p}}{4}
$$

If the system contains only one species, Eq. 2 can be simplified as:

$$
N_{D G M}=-\frac{1}{R T}\left(D_{K}+\frac{K_{0}}{\eta} P\right) \frac{\partial P}{\partial r} .
$$

\subsubsection{Generalized Maxwell-Stefan Model}

The GMS model is based on the assumption that the movement of species is caused by a driving force balanced by the friction that the moving species experience both from each other and from their surroundings. The diffusion of adsorbed species satisfies[31]:

$$
-\frac{\theta_{i}(1-\varepsilon)}{R T} \nabla \mu_{i}=\sum_{j=1, j \neq i}^{n} \frac{\theta_{j} N_{i}^{s}-\theta_{i} N_{j}^{s}}{\rho_{p} q_{s a t} D_{i j}^{s}}+\frac{N_{i}^{s}}{\rho_{p} q_{s a t} D_{i}^{s}},
$$

where $\mu_{i}$ is the chemical potential of $i(\mathrm{~J} / \mathrm{mol}), \theta_{i}$ is the fractional coverage, $\rho_{p}$ is the density of particle or solid skeleton $\left(\mathrm{kg} / \mathrm{m}^{3}\right), q_{\text {sat }}$ is the saturation surface concentration $\left(\mathrm{mol} / \mathrm{m}^{3}\right), D_{i j}^{s}$ is the Maxwell-Stefan counter-sorption diffusivity $\left(\mathrm{m}^{2} / \mathrm{s}\right)$, and $D_{i}^{s}$ is the Maxwell - Stefan diffusivity of species $i\left(\mathrm{~m}^{2} / \mathrm{s}\right)$. The surface fluxes $N_{i}^{s}$ of the diffusing adsorbed species are defined as:

$$
N_{i}^{s}=(1-\varepsilon) q_{\text {sat }} \theta_{i} \mathbf{u}_{i},
$$

where $\mathbf{u}_{i}$ is species velocity $(\mathrm{m} / \mathrm{s})$. Assuming equilibrium between the surface and the bulk phase, the following relationship for the surface chemical potential $\mu_{i}$ of species $i$ holds:

$$
\mu_{i}=\mu_{i}^{0}+R T \ln \left(f_{i}\right)
$$


where $\mu_{i}^{0}$ is the chemical potential in the chosen standard state and $f_{i}$ is the fugacity of species $i$ in the bulk fluid mixture $\left(P_{a}\right)$. For not too high system pressures, the component partial pressures, $P_{i}$, can be used instead of the component fugacity. Then the surface chemical potential gradients can be expressed in terms of the gradients of the surface occupancies by introduction of the matrix of thermodynamics factors:

$$
\frac{\theta_{i}}{R T} \nabla \mu_{i}=\sum_{j=1}^{n} \Gamma_{i j} \nabla \theta_{j}
$$

and the elements of thermodynamic matrix $\Gamma$ can be expressed as:

$$
\Gamma_{i j} \equiv \theta_{i} \frac{\partial \ln P_{i}}{\partial \theta_{j}}
$$

Assuming that the Langmuir equation to be valid and the adsorption equilibrium to be established, the fractional coverage $\theta_{i}$ can be written in terms of the Langmuir parameters:

$$
\theta_{i}=\frac{q_{i}}{q_{s a t}}=\frac{b_{i} P_{i}}{1+\sum_{j=1}^{n} b_{j} P_{j}},
$$

where $b_{i}$ is the Langmuir constant $\left(P_{a}^{-1}\right), q_{i}=q_{m, i} /(1-\varepsilon)$ is the solid volume dependent adsorbed phase concentration $\left(\mathrm{mol} / \mathrm{m}^{3}\right)$, and $q_{m, i}$ is the equilibrium mass dependent loading which is measured during the Langmuir adsorption experiment $\left(\mathrm{mol} / \mathrm{m}^{3}\right)$.

Based on Eq. 6 and Eq. 9, for a single component surface diffusion, the molar flux of surface diffusion is:

$$
N_{G M S}=(1-\varepsilon) q_{s a t} \frac{D_{s}}{1-\theta} \nabla \theta,
$$

where $D_{s}$ is the Maxwell-Stefan surface diffusivity $\left(\mathrm{m}^{2} / \mathrm{s}\right)$. The Langmuir equation (Eq. 11) can be simplified to:

$$
\theta=\frac{q}{q_{s a t}}=\frac{b P}{1+b P}
$$

Based on Eq. 13, the gradient of the adsorbed phase concentration can be further expressed in terms of the partial pressure gradient as follows:

$$
\frac{\partial q}{\partial r}=q_{s a t} \frac{b}{(1+b P)^{2}} \frac{\partial P}{\partial r},
$$


where $r$ represents the pore radius $(m)$. Substituting Eq. 14 to Eq. 12 , the surface diffusion flux in terms of partial gradient satisfies:

$$
N_{G M S}=(1-\varepsilon) q_{s a t} \frac{b D_{s}}{1+b P} \frac{\partial P}{\partial r} .
$$

For a single gas species the combination of the DGM (Eq. 5) and the GSM (Eq. 15) results in the total flux:

$$
N_{\text {total }}=N_{D G M}+N_{G M S}=-\left(\frac{1}{R T}\left(D_{K}+\frac{K_{0}}{\eta} P\right)+(1-\varepsilon) q_{s a t} \frac{b D_{s}}{1+b P}\right) \frac{\partial P}{\partial r},
$$

and the apparent permeability, $k_{a p p}$ satisfies:

$$
m_{\text {total }}=N_{\text {total }} M \pi\left(\frac{d_{p}^{2}}{4}\right)=\rho_{g} \pi\left(\frac{d_{p}^{2}}{4}\right) \frac{K_{a p p}}{\eta} \frac{\partial P}{\partial r},
$$

where $m_{\text {total }}$ is the total mass flow rate $(\mathrm{kg} / \mathrm{s})$. As the surface diffusion of adsorbed gas only happens in organic matter, substituting Eq. 5 into Eq. 17, the apparent permeability of inorganic matter is:

$$
K_{\text {app }, \text { iom }}=\frac{\eta M}{\rho_{g}}\left(\frac{1}{R T}\left(D_{K}+\frac{K_{0, i o m}}{\eta} P\right)\right),
$$

and with Eq. 16 and Eq. 17, the apparent permeability of organic matter is:

$$
K_{a p p, o m}=\frac{\eta M}{\rho_{g}}\left(\frac{1}{R T}\left(D_{K}+\frac{K_{0, o m}}{\eta} P\right)+(1-\varepsilon) q_{s a t} \frac{b D_{s}}{1+b P}\right) .
$$

\subsection{Expectation-Maximization (EM) algorithm}

The pore size distribution of shale matrix is a combination of the pore size distributions within the IOM and OM. The range of pore sizes, however, is different in the two components, with pores in the OM an order of magnitude smaller than those in the IOM[34. Therefore, the pore structures in the $\mathrm{OM}$ and IOM need to be distinguished. Then gas flow with and without surface diffusion of adsorbed gas can be simulated using the GMS and DGM, respectively.

Current nitrogen adsorption tests indicate that the pore size distributions in shale usually satisfy double-mode distributions [35] and the assumption of Gaussian distribution for probability distribution function (PDF) of pore size in rocks has been reported in several studies 34 [36]. Under the Gaussian 
mixtures model(GMM) assumption, the Expectation-Maximization (EM) algorithm used by Naraghi and Javadpour 34] is applied here to obtain the pore size distribution in both the IOM and OM. The EM algorithm is an iterative algorithm that starts from the initial estimation of parameters and proceeds to iteratively update those parameters until the convergence is reached. Each iteration consists of an Expectation-step and a Maximization-step.

\subsubsection{Expectation step}

In the expectation step, the probability that data point $i$ belongs to cluster $j$ can be calculated using the following:

$$
w_{j}^{(i)}=\frac{g_{j}(x) \Phi_{j}}{\sum_{l=1}^{k} g_{l}(x) \Phi_{l}},
$$

where $w_{j}^{(i)}$ is the probability that example $i$ belongs to cluster $j, k$ is the number of clusters, $\Phi_{j}$ is the fraction of the dataset belonging to cluster $j$, and $g_{j}(x)$ is the probability density function of a multivariate Gaussian which satisfies:

$$
g_{j}(x)=\frac{1}{\sqrt{(2 \pi)^{n}\left|\sum_{j}\right|}} e^{\frac{1}{2}\left(x-\mu_{j}\right)^{T} \sum_{j}^{-1}\left(x-\mu_{j}\right)},
$$

where $x$ is the input vector, $n$ is the input vector length, $\sum_{j}$ is the covariance matrix for cluster $j$, and $\mu_{j}$ is the mean of cluster $j$.

\subsubsection{Maximization step}

In the Maximization step, the cluster covariances and means based on the probabilities calculated in the Expectation step are calculated. The updated parameters are expressed in the following equations:

$$
\begin{gathered}
\Phi_{j}^{(\text {new })}=\frac{1}{m} \sum_{i=1}^{m} w_{j}^{(i)}, \\
\mu_{j}^{(\text {new })}=\frac{\sum_{i=1}^{m} w_{j}^{(i)} x^{(i)}}{\sum_{i=1}^{m} w_{j}^{(i)}}, \\
\sum_{j}^{(\text {new })}=\frac{\sum_{i=1}^{m} w_{j}^{(i)}\left(x^{(i)}-\mu_{j}\right)\left(x^{(i)}-\mu_{j}\right)^{T}}{\sum_{i=1}^{m} w_{j}^{(i)}} .
\end{gathered}
$$




\subsection{Generalized lattice Boltzmann model}

Nithiarasu et al.[37] proposed a generalized N-S equation for isothermal incompressible fluid flow in porous media which can be expressed as follows:

$$
\begin{gathered}
\nabla \cdot \mathbf{u}=0, \\
\frac{\partial \mathbf{u}}{\partial t}+(\mathbf{u} \cdot \nabla)\left(\frac{\mathbf{u}}{\varepsilon}\right)=-\frac{1}{\rho} \nabla(\varepsilon P)+v_{e} \nabla^{2} \mathbf{u}+\mathbf{F},
\end{gathered}
$$

where $\mathbf{u}$ and $P$ are the volume-averaged velocity and pressure, respectively. $v_{e}$ is an effective viscosity equals to the shear viscosity of fluid $v$ times the viscosity ratio $J\left(v_{e}=v J\right)$. In the present study, $\varepsilon$ is assumed to be the effective porosity that is responsible for gas flow, and "dead-end" pores are not included. F represents the total body force due to the presence of the porous media and other external forces, which is given by:

$$
\mathbf{F}=-\frac{\varepsilon v}{K} \mathbf{u}-\frac{\varepsilon F_{\epsilon}}{\sqrt{K}}|\mathbf{u}| \mathbf{u}+\varepsilon \mathbf{G}
$$

where $\mathbf{G}$ is the external force, $F_{\epsilon}$ is the geometric function and $K$ is the local permeability. To incorporate the effects of Knudsen diffusion and surface diffusion, Eq. 27 is modified by substituting $K$ with apparent permeability $K_{a p p}$ based on the idea proposed by Chen et al[25]. Without considering the nonlinear drag force term as the flow rate is extremely small in shale matrix, the body force is given by:

$$
\mathbf{F}=-\frac{\varepsilon v}{K_{a p p} \mathbf{u}}+\varepsilon \mathbf{G}
$$

and $K_{a p p}$ can be calculated based on Eq. 18 and Eq. 19 for IOM and OM, respectively.

To solve the generalized N-S equation, Guo and Zhao[26] proposed a generalized LBE as follows:

$$
f_{i}\left(\mathbf{x}+\mathbf{e}_{i} \Delta t, t+\Delta t\right)-f_{i}(\mathbf{x}, t)=-\frac{1}{\tau}\left[f_{i}(\mathbf{x}, t)-f_{i}^{e q}(\mathbf{x}, t)\right]+\Delta t F_{i},
$$

where $f_{i}(\mathbf{x}, t)$ is the distribution function for the particle with velocity $\mathbf{e}_{i}$ at position $\mathbf{x}$ and time $t, \Delta t$ is the time increment, and $\tau$ is the relaxation time. In two dimensional and nine velocity (D2Q9) model, the discrete velocity $\mathbf{e}_{i}$ 
and the two parameters $c_{0}$ and $c_{1}$ are given by:

$$
c_{0}=\frac{1}{2}\left(1+\varepsilon \frac{\Delta t}{2} \frac{v}{K_{a p p}}\right),
$$




$$
c_{1}=\varepsilon \frac{\Delta t}{2} \frac{F_{\epsilon}}{\sqrt{K_{a p p}}} .
$$

In the simulation of gas flow through a porous system, the GLBM model can be employed by simply replacing the usual computational lattices with porous lattices in the domain occupied by the porous medium in both 2-D and 3-D situations 38. In this study, the porosity remains the same in each component, and each porous lattice in the simulation domain is characterized by a pore radius based on the pore size distribution in OM and IOM. The local $K_{a p p}$ and its components such as $K_{0}$ or $K_{\text {Knudsen }}$ of every computational lattice are calculated based on Eqs. 18 and 19, and the permeability of the porous structure is obtained by applying Darcy's law to the entire domain based on the velocity field. The advantages of the above GLB model are as follows: Firstly, the modelling of pore space and the impermeable solid can be achieved by assigning porosity as unity and by assigning the drag force as infinity, respectively. Hence, the GLBM can account for the pore connectivity. Secondly, without invoking any boundary conditions, it can automatically simulate the interfaces between different components in shale matrix with spatially variable porosity and pore size distribution. Finally, different nodes in the shale matrix are fully accounted for and the Knudsen diffusion as well as surface diffusion can be easily considered in the model. For more details of the generalized N-S equation with slippage effect and the LB model, one can refer to our previous work 25] 27].

\section{Validation}

\subsection{Validation of DGM-GMS}

It is not an easy task to evaluate the accuracy of DGM-GMS model in simulating gas flow in organic shale as there is an insufficient experimental data available in the literature. However, some experimental studies were proposed to verify the feasibility of DGM-GMS in modelling gas transport in mesoporous solids such as silicas and aluminas in the presence of adsorption fields. In this study, the experimental data of Carbon dioxide flowing through the porous Vycor glass membrane under temperature 293K and $343 \mathrm{~K} 33$ were used here to validate the formulation to calculate the apparent permeability of organic matter with surface diffusion considered(Eq. 19). The structure properties and geometry of the Vycor membrane are shown in Table 1 
Table 1: Structure properties of the Vycor membrane

\begin{tabular}{c|c}
\hline Inner membrane radius $r_{1}(\mathrm{~mm})$ & 3.9 \\
\hline Outer Membrane radius $r_{2}(\mathrm{~mm})$ & 5 \\
\hline Membrane length $L(\mathrm{~mm})$ & 100 \\
\hline Apparent density $\rho_{a}\left(\mathrm{~g} / \mathrm{cm}^{3}\right)$ & 1.472 \\
\hline skeleton density $\rho_{p}\left(\mathrm{~g} / \mathrm{cm}^{3}\right)$ & 2.057 \\
\hline Porosity & 0.2842 \\
\hline The ratio of porosity to tortuosity $\varepsilon / \tau$ & 0.03 \\
\hline
\end{tabular}

The $\mathrm{CO}_{2}$ adsorption isotherms were modelled by Langmuir equation, and the obtained parameters are given in Table 2.

Table 2: Langmuir parameter of $\mathrm{CO}_{2}$

\begin{tabular}{c|c|c|c}
\hline $\mathrm{T}(\mathrm{K})$ & $D_{s}\left(\mathrm{~m}^{2} / \mathrm{s}\right)$ & $q_{\text {sat }}\left(\mathrm{mol} / \mathrm{m}^{3}\right)$ & $b\left(P_{a}^{-1}\right)$ \\
\hline $293 \mathrm{~K}$ & $2.2 \times 10^{-9}$ & 3135 & $0.467 \times 10^{-5}$ \\
$343 \mathrm{~K}$ & $2.8 \times 10^{-9}$ & 2255 & $0.191 \times 10^{-5}$ \\
\hline
\end{tabular}

Experimental data and calculations of total molar flow rate, $N_{\text {total }}$ are given in Fig. 2 and Fig. 3. It can be seen that the simulation results based on DGM-GMS match reasonably well with experimental observations, with the deviations below 15\%. As predicted by theory a slight decrease of the permeation data was observed for increasing pressure at different temperatures. It can also be concluded from Fig. 2 and Fig. 3 that for the given experimental conditions, the surface transport was only slightly smaller than the transport in the bulk phase, and the DGM without surface diffusion will lead to a significant underestimation of the permeation (see dash lines in Fig. 2 and 3). Noteworthy, although the solid properties, the adsorption and surface diffusion properties of Vycor glass are different from those of organic shale samples, the validation still can confirm that DGM-GMS in which the surface diffusion is considered can provide a better estimation of gas flow compared to the models without considering surface diffusion. 


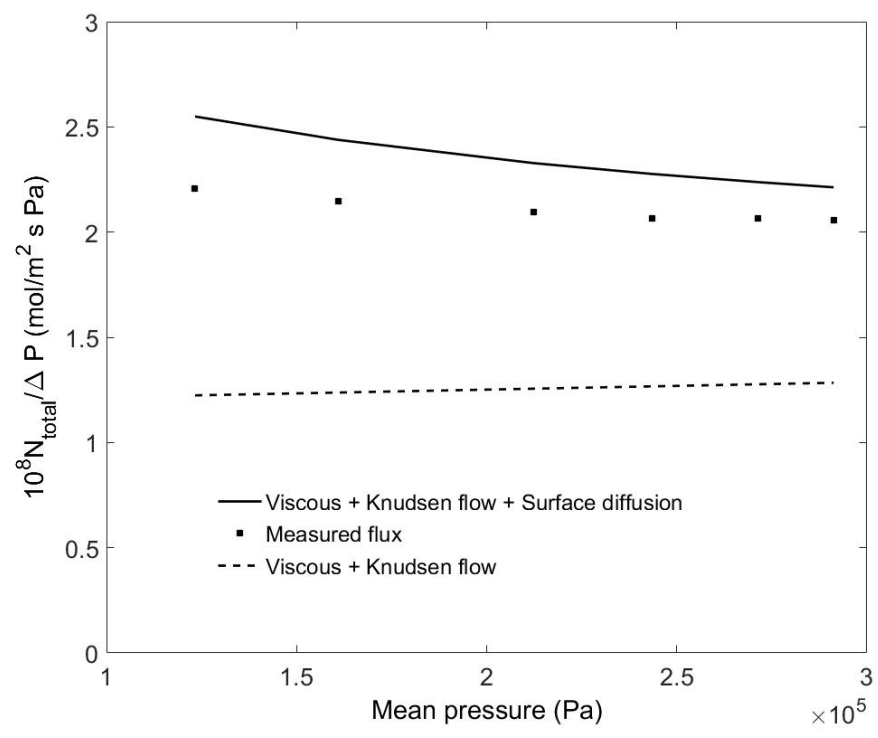

Figure 2: Permeation of carbon dioxide through Vycor at $293 K$. The data denoted by the solid squares were reported by Tuchlenski et al. 33.

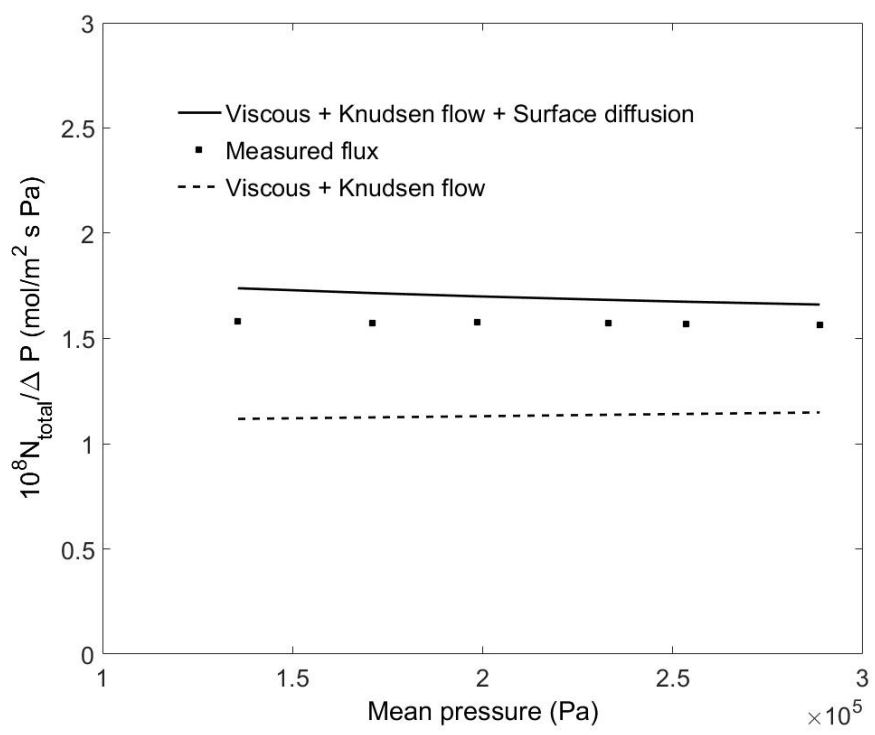

Figure 3: Permeation of carbon dioxide through Vycor at $343 K$. The data denoted by the solid squares were reported by Tuchlenski et al. 33. 


\begin{tabular}{l|c|c|c|c|c|c}
\multicolumn{8}{c}{ Table 3: Parameters of test clusters } \\
\hline & $\mu(n m)$ & $\sigma(n m)$ & Fraction & $\mu_{E M}(n m)$ & $\sigma_{E M}(n m)$ & Fraction $_{E M}$ \\
\hline Set 1 & 10 & 1 & 0.25 & 9.8848 & 0.9886 & 0.2418 \\
\hline Set 2 & 20 & 4 & 0.75 & 19.6846 & 4.0804 & 0.7582 \\
\hline
\end{tabular}

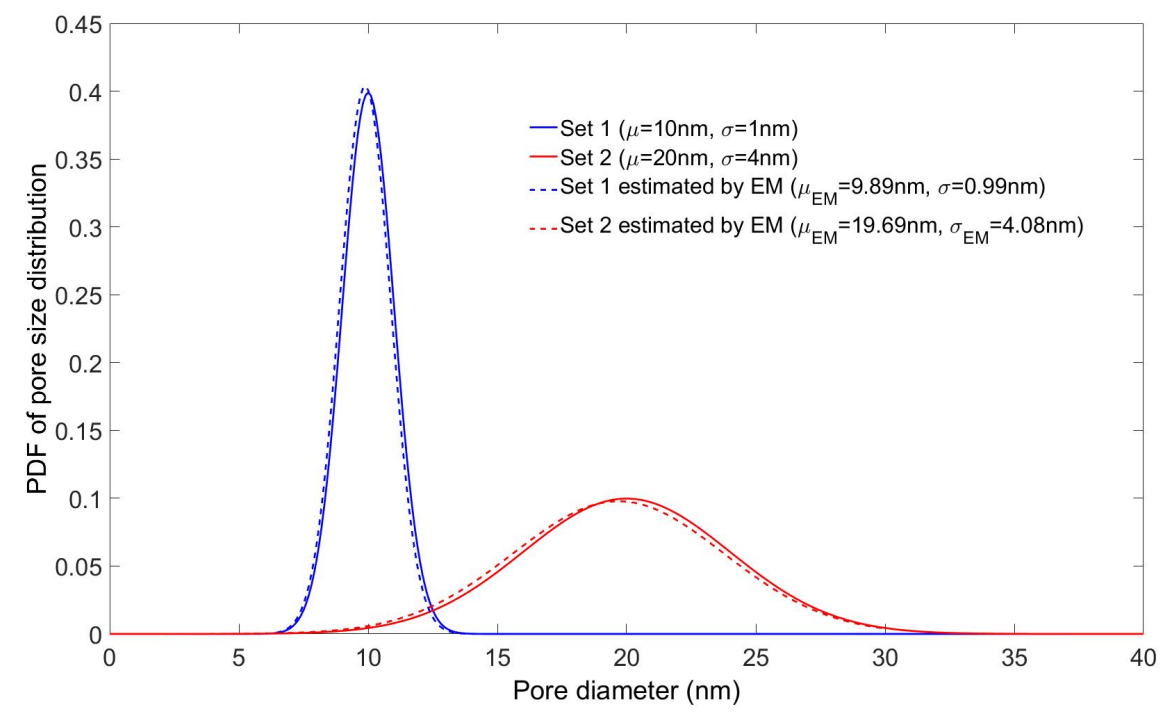

Figure 4: PDF of two clusters with different mean pore sizes and standard deviations

\subsection{Validation of EM algorithm}

To validate the accuracy of the EM algorithm for classifying pore size distribution in each component, a two-cluster Gaussian Mixture with different mean pore sizes $(\mu)$ and standard deviations $(\sigma)$ are tested. The parameters of two clusters and the calculated results are listed in Table 3 . The comparison is shown in Fig. 4. The simulation results estimated based on the EM algorithm are comparable to the original data.

Table 3: Parameters of test clusters

\footnotetext{
Figure 4: PDF of two clusters with different mean poresizes and standard deviations
}

\section{Results and Discussion}

Different from the previous studies which focus on the influence of porosity, tortuosity and adsorption phenomenon[4] [27][39], this study details the surface diffusion phenomenon. The D2Q9 model is employed due to its simplicity and efficiency. Firstly the GLBM is used to simulate the $K_{a p p}$ of 
both the IOM and OM, and then the base case data of an Eagle Ford Shale sample 34 are applied to analyze the $K_{a p p}$ of reconstructed shale. The external body force is calculated according to $G=\Delta P / L / \rho$, and the extrapolated pressure boundary conditions [40] are applied to the left and right boundaries of the simulation domain to specify the inlet and outlet pressure respectively. Periodic boundary conditions are applied to the top and bottom boundaries parallel to the flow direction. The conversion from lattice units to physical units is given in the following way. The unit of length is given by the lattice resolution $\delta x$, the unit of time, $\delta t$, is derived from the kinematic viscosity. Considering that the kinematic viscosity has the dimensions of length squared over time, we have:

$$
v_{p h y}=v \delta x^{2} / \delta t,
$$

where the kinematic viscosity in lattice unit can be calculated using Eq. 34 and the kinematic viscosity in physical unit is calculated using a open software called Peace Software. And then the scaling for other parameters such as velocity and permeability can be obtained based on $\delta x$ and $\delta t$.

\subsection{Permeability of IOM and $O M$}

Based on Eq. 18 and Eq. 19 , it is evident that $K_{a p p}$ of the IOM and the OM depend both on pressure and pore radius. $K_{a p p, o m}$ also depends on the gas adsorption properties. In this section, the change of $K_{a p p}$ with $P$ and $r$ both in OM and IOM as well as the variation of $K_{a p p, o m}$ with Langmuir parameters are discussed. The porosity remains constant in each component and each lattice is given a pore radius based on the pore size distribution which is assumed to be Gaussian.

\subsubsection{Permeability of IOM}

Fig. 5 shows the variation of $K_{a p p, i o m}$ and the ratio of $K_{a p p, i o m}$ to intrinsic permeability, $K_{0, i o m}$ with the mean pore radius of IOM, and the input parameters are listed in Table 4. Based on Fig. 5, one can observe that with the increase of the mean pore radius, $K_{a p p, i o m}$ increases, so does its rate of change. $K_{a p p, i o m} / K_{0, i o m}$ and its slope, however, decrease with the increase of mean pore radius. When the mean pore radius approaches $100 \mathrm{~nm}$, the gas flow becomes continuum, and $K_{a p p, i o m}$ approximately equals $K_{0}$. The simulation results clearly show the effect of Knudsen diffusion on the gas transport in IOM, especially when pore radius is smaller than $100 \mathrm{~nm}$. Also 
Table 4: Input parameters of IOM

\begin{tabular}{c|c}
\hline Inlet pressure $P_{\text {in }}(\mathrm{MPa})$ & 22 \\
\hline Outlet pressure $P_{\text {out }}(\mathrm{MPa})$ & 20 \\
\hline Viscosity of Methane at outlet $\left(10^{-6} \mathrm{~Pa} \cdot \mathrm{s}\right)$ & 18.231 \\
\hline Tortuosity of IOM & 2 \\
\hline Porosity of IOM & 0.04 \\
\hline Length $\times$ Width $(\mathrm{cm} \times \mathrm{cm})$ & $3.2 \times 1.6$ \\
\hline
\end{tabular}

the deviation of $K_{a p p \text {,iom }}$ from $K_{0, \text { iom }}$ indicates that the permeability of IOM in shale will be underestimated if the Knudsen diffusion is ignored.

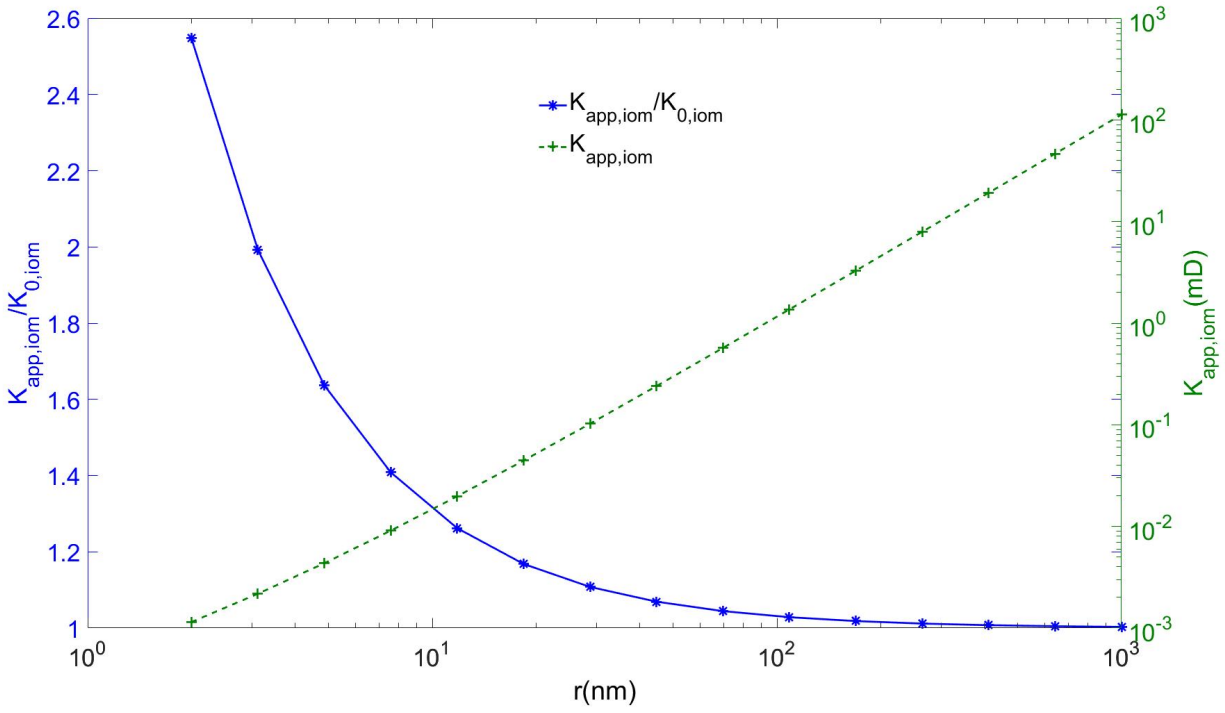

Figure 5: Variation of $K_{a p p, i o m}$ and $K_{a p p, i o m} / K_{0, i o m}$ with mean pore radius, $r . P_{i n}=$ $22 M P a$ and $P_{\text {out }}=20 M P a$.

Fig. 6 shows the variation of $K_{a p p, i o m}, K_{0, i o m}$, and $K_{\text {Knudsen,iom }}$ with the average pressure, where $K_{0, \text { iom }}$ and $K_{\text {Knudsen,iom }}$ are components from viscous flow (intrinsic permeability) and Knudsen diffusion, respectively. The average radius is $2 \mathrm{~nm}$ and the standard deviation is $0.25 \mathrm{~nm}$. As can be seen in Fig. 6, as the average pressure increases, the intrinsic permeability does not change, but $K_{\text {Knudsen,iom }}$ (and hence $K_{\text {app,iom }}$ ) decreases. This result is important for shale gas production, as the reservoir is depleted and 
the reservoir pressure decreases, $K_{a p p, i o m}$ deviates from the intrinsic permeability owing to high contribution of Knudsen diffusion at zones with low pressures, and gas transport in these zones therefore is predominantly controlled by Knudsen diffusion. Fig 6 also indicates that permeability of IOM is a function of reservoir pressure, and the permeability must be considered as a dynamic reservoir parameter and updated accordingly as the reservoir is being depleted.

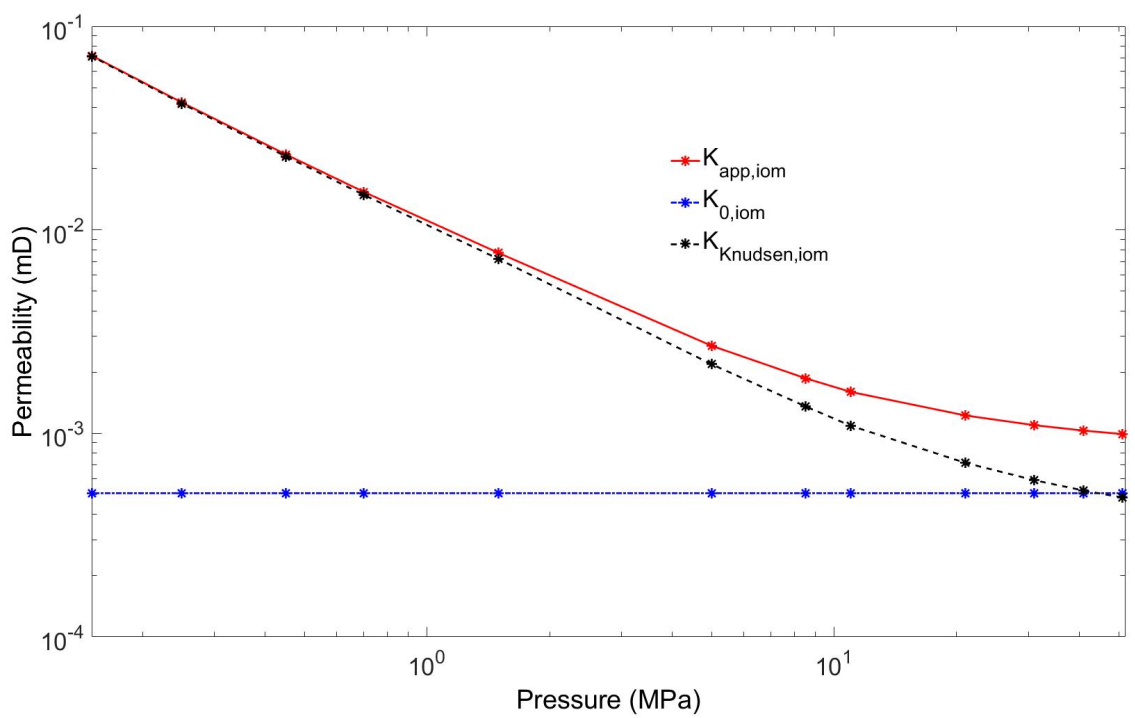

Figure 6: Variation of $K_{a p p, i o m}$ and its components with average pressure. The average pore radius is $2 \mathrm{~nm}$, and the average pressure is calculated based on $\left(P_{\text {in }}+P_{\text {out }}\right) / 2$.

Similar dependencies on pore sizes and pressure have been observed by other studies considering conductivity of a single channel[41] and bundle of channels or nanopore networks 42 .

\subsubsection{Permeability of $O M$}

Adsorbed gas and surface diffusion in OM are drawing more attention recently. Various studies have confirmed that the adsorption can change $K_{a p p, o m}$ of shale matrix and the surface diffusion is an important transport mechanism at reservoir conditions [4] [43]. In some treatments, the surface diffusion is considered as an extra flux in capillary models 21] 14] 39. However the sensitivity of permeability to adsorption and surface diffusion are seldom 
mentioned. In others, the adsorbed gas is modelled by taking some pore space and therefore reducing the local pore size 27 44] 7]. In other words, if adsorbed gas is assumed to pre-exists in OM, the intrinsic permeability will increase with the decrease in pressure because the desorbed gas will release some pore space 44. Nonetheless, no consensus on the volume occupied by adsorbed gas exists in these treatments 14 44 39, also the contribution of the surface diffusion is ignored. In this study, with the introduction of DGM-GMS model, the effect of surface diffusion on $K_{a p p, o m}$ can be easily considered, and based on the assumption that the total flux $N_{\text {total }}$ is the sum of $N_{D G M}$ and $N_{G M S}$, the ambiguity in the adsorption layer thickness can be avoided. As mentioned above, the contribution of surface diffusion is affected by parameters regarding the Langmuir adsorption model and the surface diffusivity. Therefore, the model parameter values of adsorbed gas and surface diffusivity for the following sensitivity analysis were carefully collected from the reported data. Specifically, $b$ and $q_{s a t}$ were collected from the previous Langmuir isothermal of shale samples and the results are presented in Table 5. Based on data in Table 5, a range of $b$ from 0.125 to $1 M P a^{-1}\left(b^{-1}\right.$ from 1 to $8 M P a)$ and a range of $q_{s a t, k}$ from 1000 to $8000 \mathrm{~mol} / \mathrm{m}^{3}$ are used for discussion in this study. For the determination of Langmuir volume $q_{s a t}$, data were treated with caution as the definition and unit of $q_{s a t}$ vary from one study to another. For instance, Eq. 40 is used to obtain $q_{s a t, k}$ if $q_{s a t, b}$ is presented in the literature.

$$
q_{s a t, k}=\frac{q_{s a t, b} \rho_{b}}{(1-\varepsilon) T O C} \frac{\rho_{C H_{4}}}{M_{C H_{4}}},
$$

where $T O C$ is the volume fraction of the kerogen content, $q_{s a t, k}$ is the mole volume of methane divided by the volume of kerogen skeleton $\left(\mathrm{mol} / \mathrm{m}^{3}\right)$, and $q_{s a t, b}=V / m_{b}$ is the volume of methane divided by the bulk mass of shale sample $\left(\mathrm{m}^{3} / \mathrm{kg}\right)$. 
Table 5: Langmuir constant given by different authors 45, 46, 47, 48, 49, 50, 51, 52.

\begin{tabular}{|c|c|c|c|c|}
\hline Reference & Sample & $\mathrm{T}(K)$ & $1 / b(M P a)$ & $q_{s a t, k}\left(\mathrm{~mol} / \mathrm{m}^{3}\right)^{\dagger}$ \\
\hline \multirow{5}{*}{ Zhang et al. 45] } & \multirow{3}{*}{ Woodford } & 309 & 3.57 & \multirow{3}{*}{3011.25} \\
\hline & & 324 & 4.76 & \\
\hline & & 339 & 7.69 & \\
\hline & \multirow{2}{*}{ Green river } & 309 & 6.67 & \multirow{2}{*}{2516.12} \\
\hline & & 324 & 7.69 & \\
\hline Mengal \& Wattenbarger 46] & Barnett & -- & 4.48 & 1817.57 \\
\hline Boulis et al. 47] & Marcellus & 322 & 3.58 & 3606.23 \\
\hline Zuber et al. 48] & New Albany & -- & 2.84 & 3340.08 \\
\hline \multirow{10}{*}{ Rexer et al. 49. } & \multirow{10}{*}{ Bornholm } & 300 & 1.65 & 7321.88 \\
\hline & & 303 & 1.68 & 6943.75 \\
\hline & & 308 & 1.50 & 6256.25 \\
\hline & & 318 & 1.68 & 5981.25 \\
\hline & & 338 & 2.30 & 5809.57 \\
\hline & & 358 & 2.60 & 5190.63 \\
\hline & & 373 & 2.60 & 4468.75 \\
\hline & & 398 & 3.06 & 3781.25 \\
\hline & & 423 & 3.10 & 3162.50 \\
\hline & & 448 & 2.83 & 2475.00 \\
\hline \multirow{3}{*}{ Heller \& Zoback [50] } & Barnett & 313 & 4.00 & 3595.83 \\
\hline & Eagleford & 313 & 4.79 & 613.81 \\
\hline & Marcellus & 313 & 3.84 & 1367.77 \\
\hline Etminan et al. [51] & -- & 323 & 6.14 & 3214.62 \\
\hline \multirow{8}{*}{$\mathrm{Hu}[52]$} & \multirow{4}{*}{ Barnett 1} & 309 & 2.94 & \multirow{4}{*}{2319.89} \\
\hline & & 324 & 4.00 & \\
\hline & & 339 & 4.76 & \\
\hline & & 349 & 5.26 & \\
\hline & \multirow{4}{*}{ Barnett 2} & 309 & 1.59 & \multirow{4}{*}{3315.13} \\
\hline & & 324 & 2.38 & \\
\hline & & 339 & 3.13 & \\
\hline & & 349 & 4.00 & \\
\hline
\end{tabular}

$\dagger$ When the properties of TOC is not given in the literature, the $q_{s a t, k}$ is calculated based on the assumption that the TOC, the porosity of Kerogen and the density of $\mathrm{OM}$ are $0.2,0.2$ and $1.65 \times 10^{3} \mathrm{~kg} / \mathrm{m}^{3}$, respectively.

377 The surface diffusion diffusivity can be measured in forms of self-diffusivity 
$D_{\text {self }}$, Maxwell-Stefan diffusivity $D_{s}$ or Fickian diffusivity $D_{f}$. From Table 6 it can be seen that $D_{f}>D_{s}>D_{\text {self }}$. The $D_{f}$ of organic shale given by Kang et al. [53] is from $1.55 \times 10^{-7}$ to $8.8 \times 10^{-6} \mathrm{~m}^{2} / \mathrm{s}$, and by Akkutlu and Fathi[54] is from $8.3 \times 10^{-8}$ to $8.8 \times 10^{-6} \mathrm{~m}^{2} / \mathrm{s}$. $D_{\text {self }}$ of organic shale given by Zhai et al. [55] is between $9.43 \times 10^{-9}$ and $11.62 \times 10^{-9} \mathrm{~m}^{2} / \mathrm{s}$ and by Yuan et al.[56] is from $2.38 \times 10^{-9}$ to $9.96 \times 10^{-9} \mathrm{~m}^{2} / \mathrm{s}$. Wu et al.[10] proposed an empirical equation to determine $D_{s}$ of methane based on the experimental data of methane-activated carbon:

$$
D_{s}=\left(8.29 \times 10^{-7}\right) T^{0.5} \exp \left(-\frac{\Delta H^{0.8}}{R T}\right),
$$

where $\Delta H$ is the isosteric adsorption heat, ranging from 12000 to $16000 \mathrm{~J} / \mathrm{mol}$ at $338.7 \mathrm{~K}$, and $D_{s}$ ranges from $6.72 \times 10^{-6}$ to $7.96 \times 10^{-6} \mathrm{~m}^{2} / \mathrm{s}$. In a most recent study, Wu et al.57] made a detailed summary of surface diffusivity of various gas under different circumstances (see Table 4 in the Ref.[57]), and extremely high surface diffusivity which is larger than $1 \times 10^{-6} \mathrm{~m}^{2} / \mathrm{s}$ has been observed in the literature [58] [59]. Based on these data, considering the specific values of surface diffusivity of shale samples are still not clear and more experiments will likely be done in the future, in this study we choose to cover a wide range of Maxwell-Stefan diffusivity to take account of more cases, and $D_{s}$ from $1 \times 10^{-9}$ to $1 \times 10^{-5} \mathrm{~m}^{2} / \mathrm{s}$ is used for the following discussions.

Table 6: Comparison of different diffusivity 60

\begin{tabular}{c|c}
\hline Self-diffusion diffusivity & $D_{\text {self }} \approx D_{0}(1-\theta)$ \\
\hline Maxwell-Stefan diffusivity & $D_{s} \approx D_{0}$ \\
\hline Fickian diffusivity & $D_{f}=\frac{D_{0}}{1-\theta}$ \\
\hline
\end{tabular}

Fig. 7 shows the variation of $K_{a p p, o m}$ and $K_{a p p, o m} / K_{0, o m}$ with $r . D_{s}, q_{s a t}$ and $b$ are set to be $5 \times 10^{-7} \mathrm{~m}^{2} / \mathrm{s}, 4000 \mathrm{~mol} / \mathrm{m}^{3}$ and $0.25 \mathrm{MPa}^{-1}$, respectively. The other inputs are the same as that listed in Table 4. $K_{\text {app,om }}$ without considering the surface diffusion is also listed in the figure for comparison. From Fig. 7 it can been seen that, the trend of $k_{a p p, o m}$ and $k_{a p p, o m} / k_{0, o m}$ is similar to that of IOM. In large pores, both Knudsen diffusion and surface diffusion can be ignored, and $K_{a p p, o m}$ equals $K_{0, o m}$. Fig. 7 also shows that the surface diffusion is the primary flow mechanism in nano-pores, and significant underestimation of permeability can be observed if the surface diffusion is 
ignored when the average pore radius is less than $10 \mathrm{~nm}$. Wu et al. 10. reported that the contribution of surface diffusion to the shale gas mass transfer can be up to $92.95 \%$ when pore radius is smaller than $2 \mathrm{~nm}$. The results presented in Fig. 7 agree well with that presented by Wu et al.[10], and the value of $K_{a p p, o m} / K_{0, o m}$ can be larger than 10 at $r<2 n m$ when surface diffusion is considered.

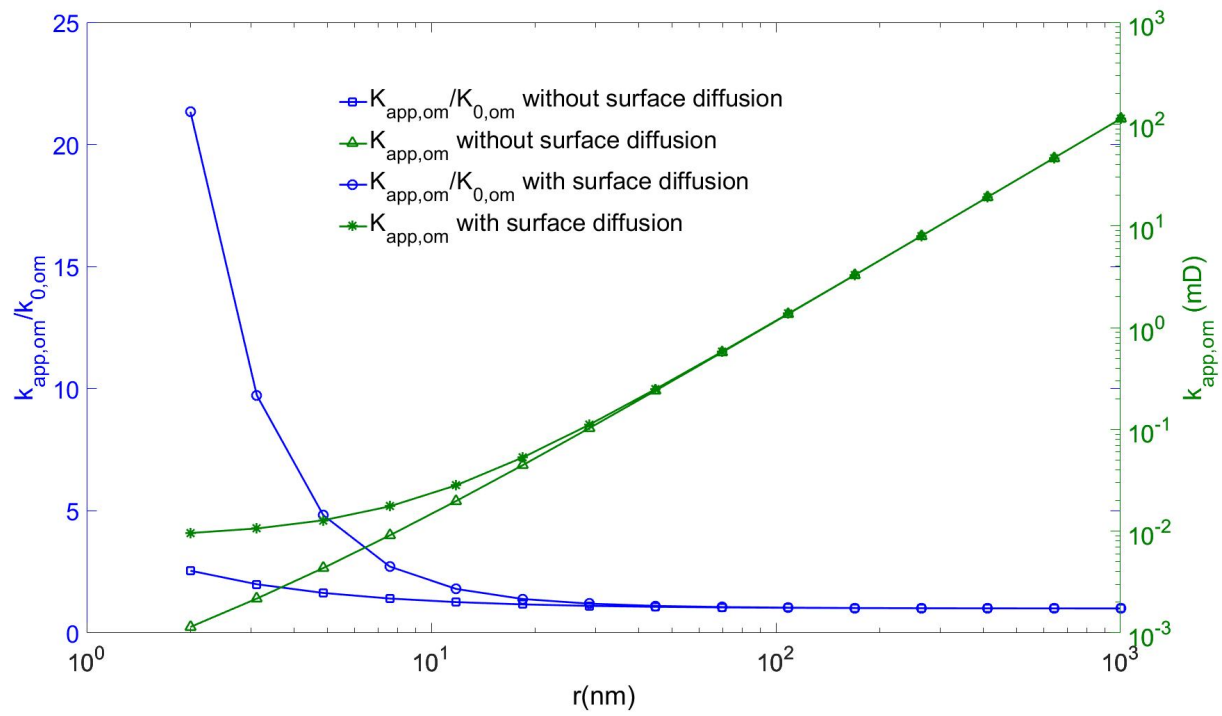

Figure 7: Variation of $K_{a p p, o m}$ and $K_{a p p, o m} / K_{0, o m}$ with mean pore radius, $\mathrm{r}$ of organic matter at $D_{s}=5 \times 10^{-7} \mathrm{~m}^{2} / \mathrm{s}, q_{\text {sat }}=4000 \mathrm{~mol} / \mathrm{m}^{3}$ and $b=0.25 \mathrm{MPa}^{-1} . P_{\text {in }}=22 \mathrm{MPa}$ and $P_{\text {out }}=20 M P a$.

Fig. 8 illustrates $K_{a p p, o m}$ and its components estimated based on DGMGMS under different average pressure conditions. The average radius used in this case is $2 \mathrm{~nm}$ with a standard deviation of $0.25 \mathrm{~nm}$. The other inputs are the same as those of Fig. 7. Fig. 8 shows that the surface diffusion decreases linearly with the increasing pressure, and the contribution from both Knudsen diffusion and surface diffusion becomes almost negligible when the pressure reaches a high level. However, the surface diffusion is the dominant mass transport mechanism in OM at low pressures, and $K_{a p p, o m}$ accounting for surface diffusion can be several times larger than that without considering it. Similar to $K_{a p p, i o m}, K_{a p p, o m}$ is sensitive to pressure and deviates further from the intrinsic permeability at lower pressure. It is typically believed that the shale gas production quickly declines from an initial high production rate 
which results from the free gas in major fractures in the first years, followed by a long tail which is controlled by accessibility of small pores of shale matrix that may last 20 years or more [61]. The increase of $K_{a p p}$ with decreasing pressure in both OM and IOM shown in this study explains why the conventional continuum models using the intrinsic permeability underestimate the production rate at the later stage. This phenomenon has been confirmed by the earlier numerical simulation studies, and more details can be found from Ref.616263.

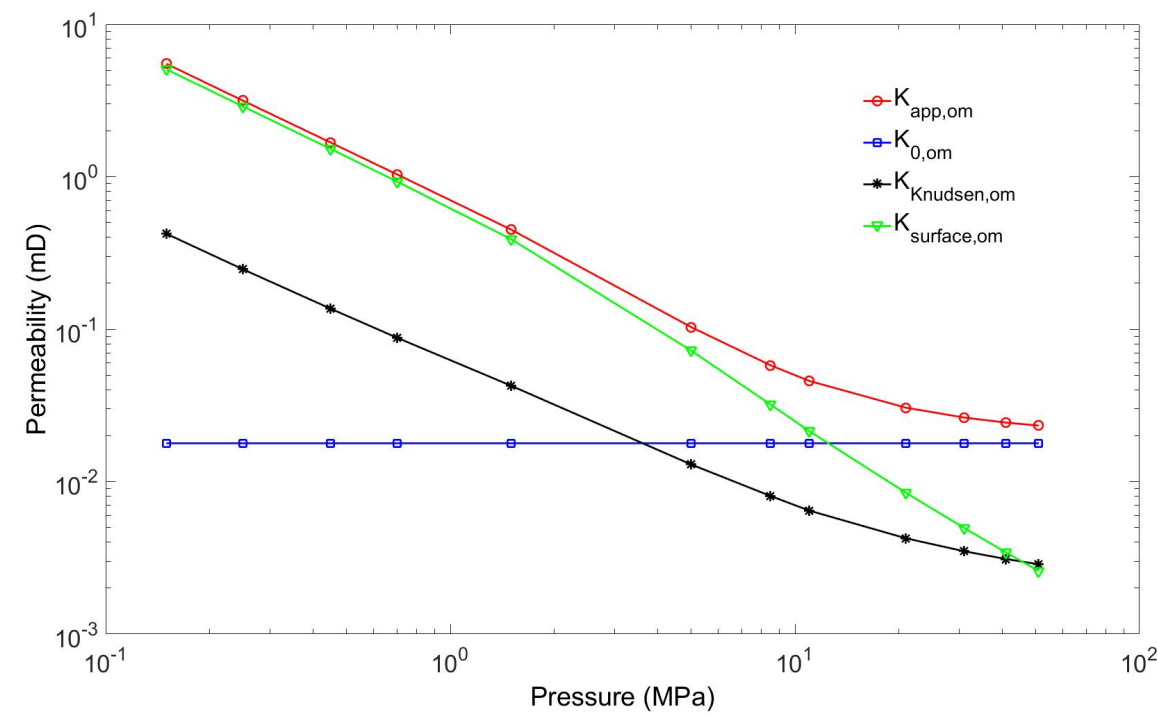

Figure 8: Variation of $K_{a p p, o m}$ and its components with average pressure at $D_{s}=5 \times$ $10^{-7} \mathrm{~m}^{2} / \mathrm{s}, q_{\text {sat }}=4000 \mathrm{~mol} / \mathrm{m}^{3}$ and $b=0.25 \mathrm{MPa}^{-1}$. The average pore radius, $r=2 \mathrm{~nm}$, and standard deviation, $\sigma=0.25 \mathrm{~nm}$.

Fig. 9 depicts $K_{a p p, o m}$ with different Langmuir parameters. $D_{s}$ is set to be $5 \times 10^{-7} \mathrm{~m}^{2} / \mathrm{s}$, the average radius is $11 \mathrm{~nm}$, and $\sigma$ is $0.25 \mathrm{~nm}$. To represent the reservoir condition, the inlet pressure is set to be $22 M P a$, and the outlet pressure is $20 \mathrm{MPa}$. As can be seen in Fig. 9, $K_{a p p, o m}$ is linearly increasing with the increase of $q_{s a t}$ and the decrease of $b^{-1}$. This is because based on Langmuir model(Eq. 13), a larger $q_{\text {sat }}$ or $b$ induces a larger amount of adsorbed gas at a certain pressure, and therefore leads to a higher surface flux. Also, the influence of $b$ on $K_{a p p, o m}$ is becoming obvious with the increase of $q_{\text {sat }}$. The results of Fig. 9 further emphasizes the impact of adsorbed gas on gas flow in OM. 


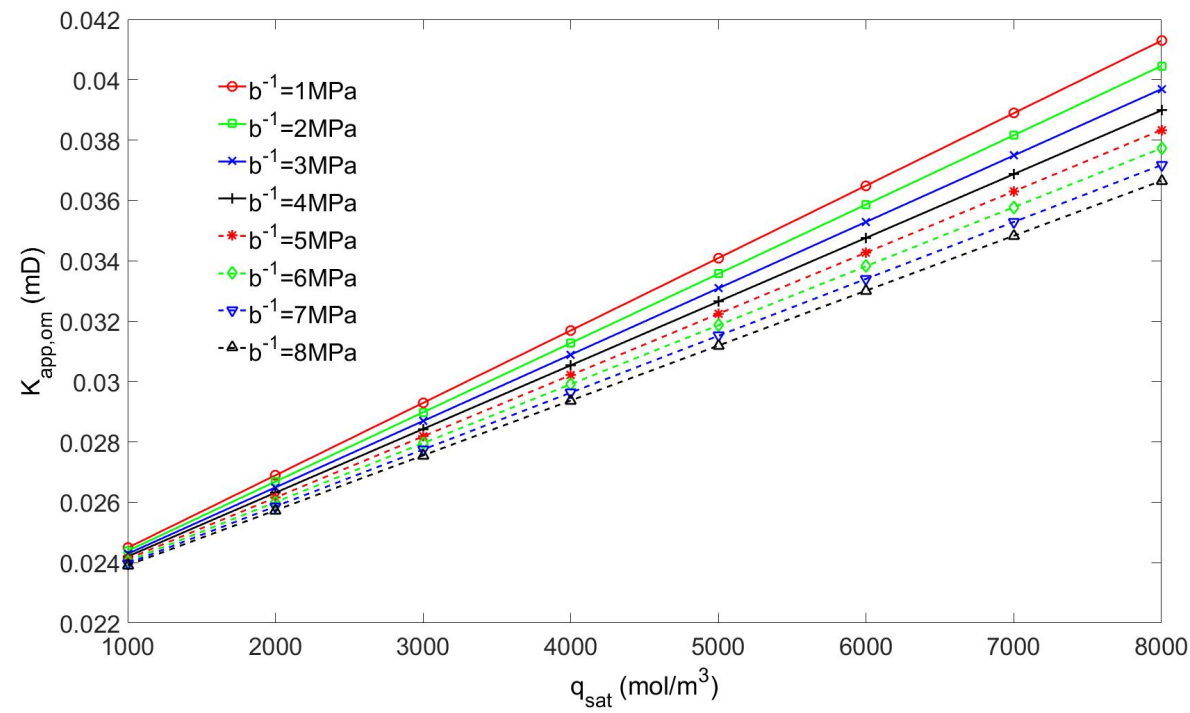

Figure 9: Variation of $K_{a p p, o m}$ with Langmuir parameters at $D_{s}=5 \times 10^{-7} \mathrm{~m}^{2} / \mathrm{s} . P_{\text {in }}=$ $22 \mathrm{MPa}$ and $P_{\text {out }}=20 \mathrm{MPa}$, the average pore radius, $r=11 \mathrm{~nm}$ and $\sigma=0.25 \mathrm{~nm}$.

The above results confirm that the flow patterns of OM differ from that of IOM, and the gas flow in OM is more complicated than that in IOM. Moreover, the variation of $K_{a p p}$ with pore radius suggests that the pore sizes corresponding to each components should be considered, and the usage of the mean pore size could be erroneous. In the following sections, the analysis based on reconstructed shale matrix consisting of both OM and IOM are performed to estimate the variation of $K_{a p p}$ with component distribution and content.

\subsection{Effects of the component distribution}

The pore size distribution of reconstructed shale sample is obtained by nitrogen intrusion test of the Eagle Ford Shale reported by Naraghi and Javadpour [34. As can be seen in Fig. 10, an evidenced bimodal trend exists in the shale sample. With a hypothesis that the pore radius of OM is smaller than that of IOM, pore size distributions in OM and IOM are extracted from Fig. 10 by using EM algorithm and are presented in Table 7. 


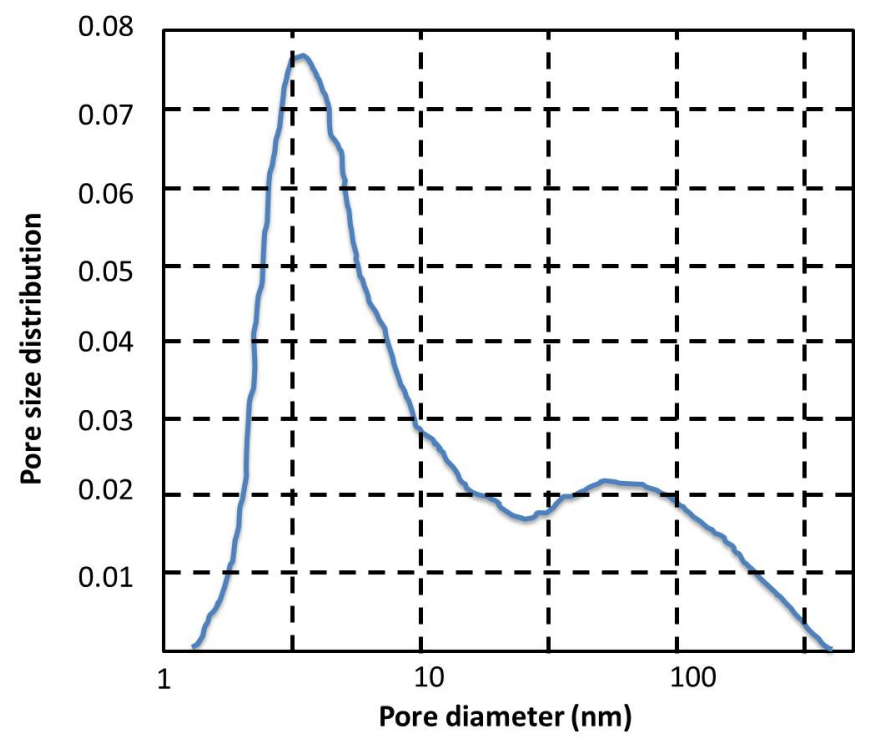

Figure 10: Pore-size distribution of the Eagle Ford Shale sample 34

Table 7: Properties of pore size distributions in OM and IOM, $\mu$ and $\sigma$ are mean and standard deviation of the log transform of the pore size shown in Fig. 10

\begin{tabular}{c|c|c|c}
\hline Region & $\mu(\mathrm{nm})$ & $\sigma(\mathrm{nm})$ & Fraction \\
\hline OM & 0.4 & 0.18 & 0.56 \\
\hline IOM & 1.4 & 0.44 & 0.44 \\
\hline
\end{tabular}

Based on the model parameters, the pore size distribution in different OM and IOM regions can be found. In order to study the effect of the distribution of each component on $K_{\text {app }}$, four cases are considered( See Fig. 11). In case 1, the OM and the IOM are placed parallel to the flow direction. In case 2 and case 3, gas passes through the OM and the IOM in sequence. In case 4 , the $\mathrm{OM}$ and the IOM are randomly distributed in the simulation domain. At a given pore size distribution and component distribution, since the EM algorithm is a stochastic process, one will get different realizations of pore sizes with each run. Therefore, For each case, multiple realizations of the same pore size distribution are generated randomly into different data sets based on the parameters listed in Table 7. The other inputs are listed in Table 8 . 
Table 8: Input parameter for gas flow in shale matrix

\begin{tabular}{c|c}
\hline$P_{\text {in }}(\mathrm{MPa})$ & 0.2 \\
\hline$P_{\text {out }}(\mathrm{MPa})$ & 0.1 \\
\hline$q_{\text {sat }}\left(\mathrm{mol} / \mathrm{m}^{3}\right)$ & 4000 \\
\hline$D_{s}\left(\mathrm{~m}^{2} / \mathrm{s}\right)$ & $1 \times 10^{-8}$ \\
\hline$b\left(\mathrm{MPa}^{-1}\right)$ & 0.25 \\
\hline Tortuosity & 2 \\
\hline Porosity of IOM & 0.02 \\
\hline Porosity of OM & 0.04 \\
\hline Length $\times$ Width $(\mu m \times \mu m)$ & $16 \times 8$ \\
\hline
\end{tabular}

The simulation results of $K_{a p p}$ for different component distributions are listed in Fig. 12, It can be seen that for each case, different data sets give rise to almost identical results, which demonstrates the numerical accuracy of the current LB model. Comparing all four cases, it can be seen that the influence of the component distribution on $K_{a p p}$ is not significant, and $K_{a p p}$ approximately ranges from $0.0845 \mathrm{mD}$ to $0.0856 \mathrm{mD}$. Nevertheless, within this small range of $K_{a p p}$, case 3 and case 2 determine the upper and lower bounds of $K_{a p p}$, respectively. It has been pointed out that gas becomes more rarefied in smaller pores under lower pressure. As the mean pore radius of OM is roughly 3 times smaller than that of IOM, accumulation of OM near the outlet (case 3) where the pressure is lower will increase the gas rarefaction, leading to a higher $K_{a p p}$. Conversely, when OM is accumulating near the inlet (case 2), the gas rarefaction in OM pores is less significant due to the high pressure. 

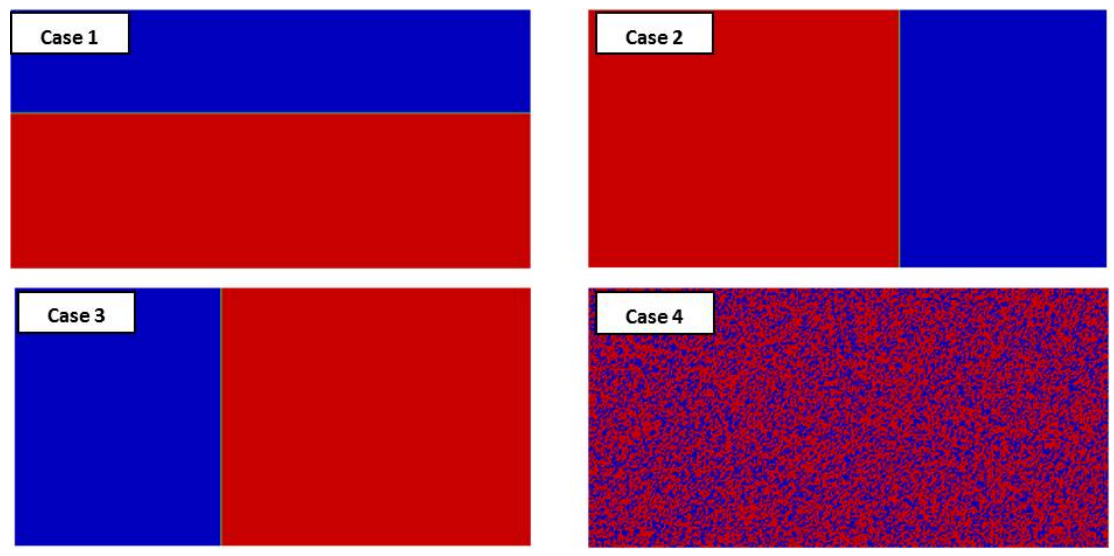

Figure 11: Structure of reconstructed 2-D shale matrix (length $\times$ width $=16 \times 8 \mu \mathrm{m}$ ). The region in red is OM, and the region in blue is IOM. The properties of OM and IOM are listed in Table 7 and Table 8 . To obtain the $K_{\text {app }}, P_{\text {in }}=0.2 M P a$ and $P_{\text {out }}=0.1 M P a$ are applied on the left and right boundaries of the simulation domain, respectively. Periodic boundary conditions are applied to the top and bottom boundaries.

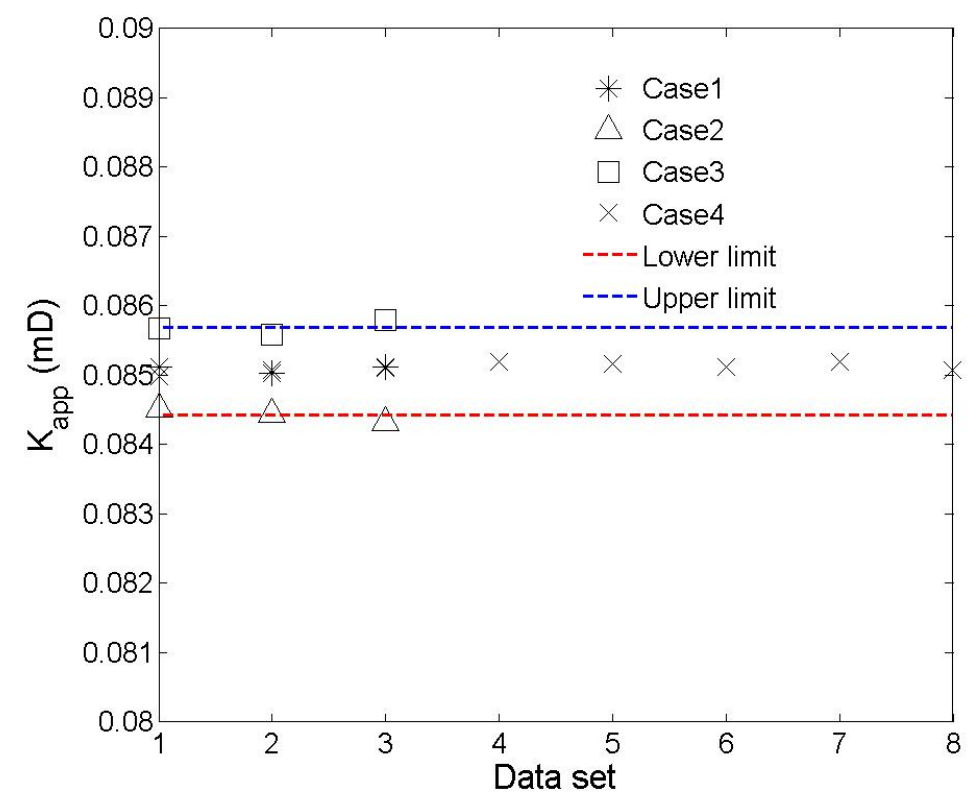

Figure 12: $K_{a p p}$ of 2-D reconstructed shale images with different structures that is shown in Fig. 11. For each case, multiple realizations of the same pore size distribution are generated randomly into different data sets. 


\subsection{Effects of the total organic content (TOC)}

To study the effects of TOC on permeability of shale, the shale matrix is constructed based on the pore size distributions listed in Table 7 with the TOC varying from 0.2 to 0.8 . The structures of the shale matrix are shown in Fig. 13, and the pore size distributions within both OM and IOM are assumed to remain constant during the simulation which are the same as that listed in Table 8.
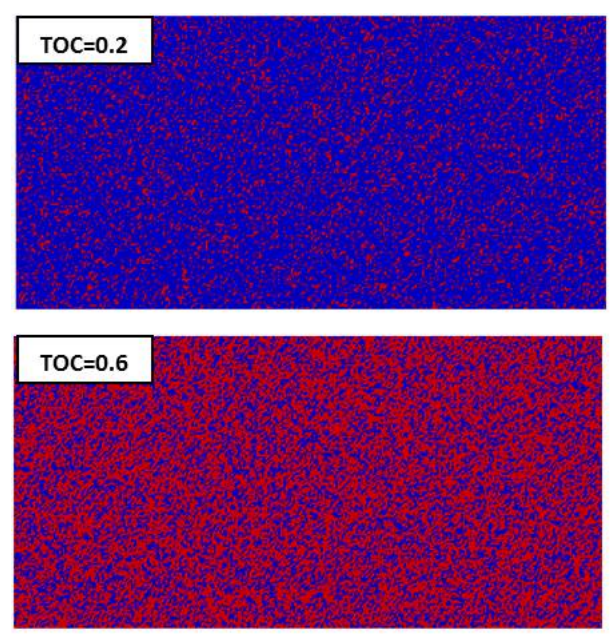
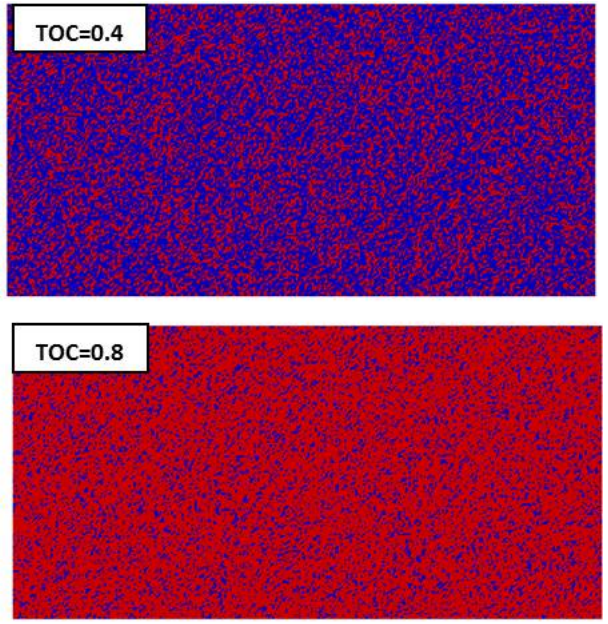

Figure 13: The structure of shale matrix with different TOC (length $\times$ width $=16 \times 8$ $\mu m)$. The region in red is OM, and the region in Blue is IOM. The properties of OM and IOM are listed in Table 7 and Table 8. To obtain the $K_{a p p}, P_{i n}=0.2 M P a$ and $P_{\text {out }}=0.1 \mathrm{MPa}$ are applied on the left and right boundaries of the simulation domain, respectively. Periodic boundary conditions are applied to the top and bottom boundaries.

As have been discussed in previous sections, $K_{a p p}$ is influenced by the Langmuir adsorption properties and the surface diffusivity, therefore the variation of $K_{a p p}$ with different $D_{s}$ are analyzed and the simulation results are presented in Fig. 14. Fig. 14 shows that the apparent permeability can be enhanced or reduced with the increase of TOC, which depends on variations in surface diffusion of adsorbed gas under different conditions. Without surface diffusion or when the surface diffusion is negligible, $K_{a p p}$ decreases with TOC as OM has smaller pores. A similar phenomenon has been observed by Naraghi and Javadpour [34] based on their stochastic permeability model for shale gas systems. With the increase of $D_{s}$, the contribution of surface diffusion to total flux is becoming more pronounced, and therefore the negative 
impact of small pore radius on $K_{a p p}$ is gradually compensated. In current simulation study, when $D_{s}$ is larger than $1 \times 10^{-8} \mathrm{~m}^{2} / \mathrm{s}$, the permeability starts to increase with TOC.

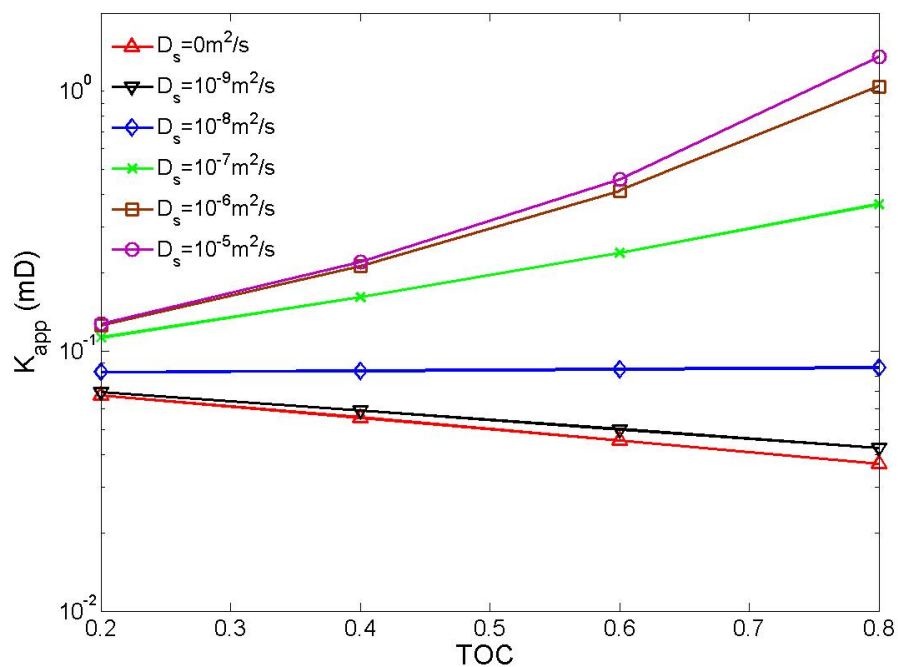

Figure 14: Variation of $K_{a p p}$ with TOC based on the structure shown in Fig. 13

The distributions of velocity magnitude $\left(\sqrt{\mathbf{u}^{2}}\right)$ in the reconstructed shale matrix with different TOC at $D_{s}=1 \times 10^{-9} \mathrm{~m}^{2} / \mathrm{s}$ and $D_{s}=1 \times 10^{-5} \mathrm{~m}^{2} / \mathrm{s}$ are shown in Figs. 15 and 16, respectively. In consistent with the results shown in Fig. 14, the velocity magnitude decreases with TOC at low surface diffusivity as OM has smaller pores, and increase with TOC at high surface diffusivity as surface diffusion is predominant. Moreover, the results of Fig. 15 show that the gas flow in reconstructed shale sample is similar to that of the rarefied gas flow, and the velocity increases from inlet to outlet when surface diffusion is small (the velocity distribution of rarefied gas flow can be found from Refs. [64]). However, at high surface diffusivity and in the situation that the surface diffusion of adsorbed gas provides a significant mass flux in addition to the Knudsen diffusion and the convection flow, some predominant pathways are formed with the increase of TOC, and the dynamic similarity of rarefied gas flow and nano-/micro domains breaks down. The velocity distribution again emphasizes the significance of surface diffusion to gas flow in organic shale. 

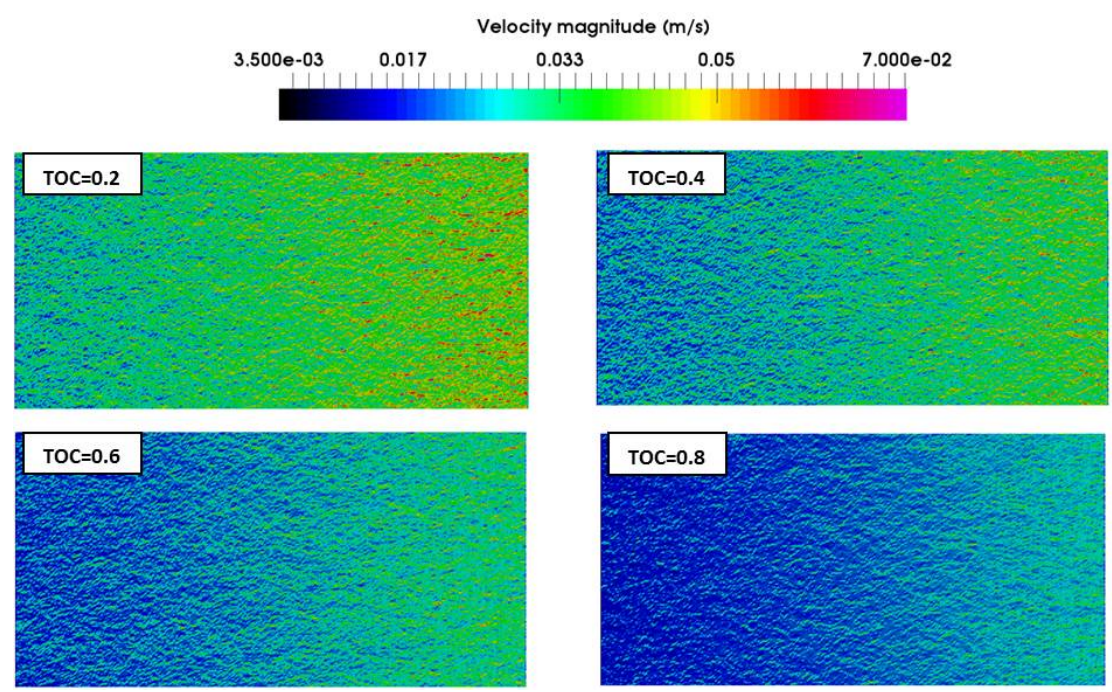

Figure 15: Velocity distribution of reconstructed 2-D organic shale structure (length $\times$ width $=16 \times 8 \mu \mathrm{m}$ ) with different TOC for the case $D_{s}=10^{-9} \mathrm{~m}^{2} / \mathrm{s} . P_{\text {in }}=0.2 \mathrm{MPa}$ and $P_{\text {out }}=0.1 \mathrm{MPa}$ are applied on the left and right boundaries of the simulation domain, respectively. Periodic boundary conditions are applied to the top and bottom boundaries.

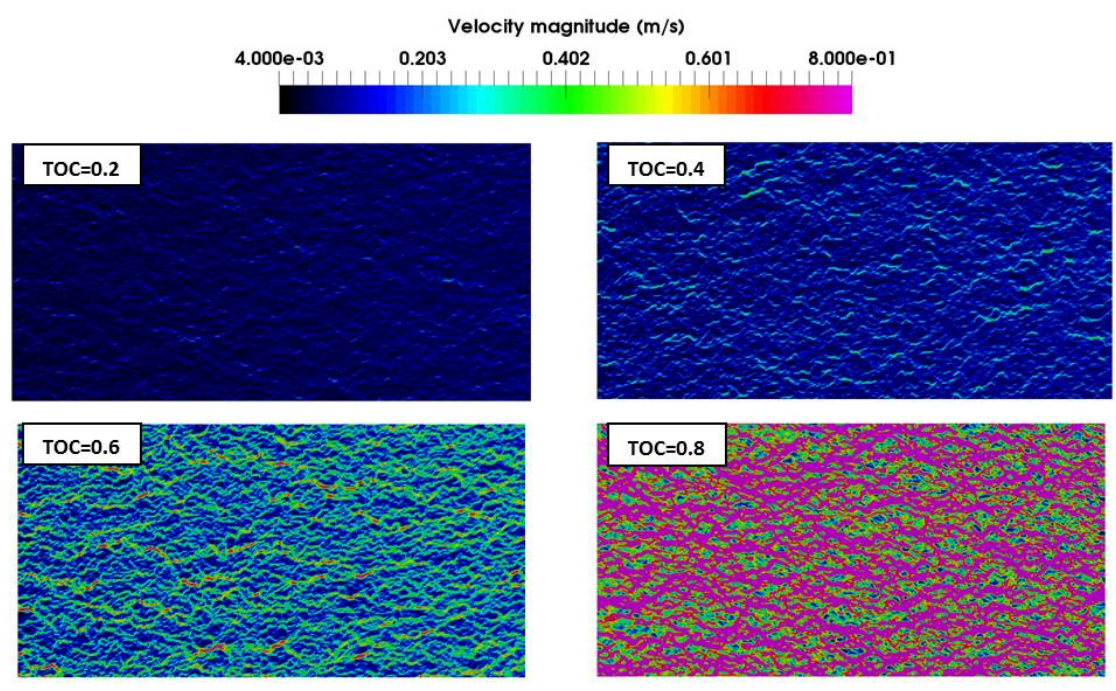

Figure 16: Velocity distribution of reconstructed 2-D organic shale structure (length $\times$ width $=16 \times 8 \mu \mathrm{m})$ with different TOC for the case $D_{s}=10^{-5} \mathrm{~m}^{2} / \mathrm{s} . P_{i n}=0.2 \mathrm{MPa}$ and $P_{\text {out }}=0.1 \mathrm{MPa}$ are applied on the left and right boundaries of the simulation domain, respectively. Periodic boundary conditions are applied to the top and bottom boundaries. 


\section{Conclusion}

In this study, a generalized lattice Boltzmann algorithm for gas flow simulation through porous shale matrix and the DGM-GMS model are employed to estimate $K_{a p p}$ that includes the surface diffusion effect. Numerical simulations of gas flow in reconstructed shale matrix containing the organic matter and inorganic matter have been carried out.

Unlike the intrinsic permeability, $K_{a p p}$ of the shale matrix is a dynamic parameter and should be adjusted as the pressure decreases in a reservoir. Permeability of the IOM increases with the increase of pore radius and the decrease of pressure. Permeability of the OM shows a similar trend with pressure and pore radius to that of the IOM. Moreover, surface diffusion in the OM can have a more important role than Knudsen diffusion and convection flow in determining the apparent permeability at low pressure and in pores smaller than $10 \mathrm{~nm}$. Furthermore, permeability shows strong dependence on the value of Langmuir parameters and surface diffusivity, which is still not well understood.

Simulation results of reconstructed shale matrix show that the apparent permeability is influenced by the distribution of OM and IOM, as well as the pore size distribution corresponding to each component. The TOC plays a more significant role in the determination of $K_{a p p}$, and its effect depends on the surface diffusivity of adsorbed gas.

The present study emphasizes that the surface diffusion in OM needs to be considered for an accurate determination of the apparent permeability, especially for very small pores at low pressure. The proposed LBM is shown to be an effective simulation tool in determining the apparent permeability of organic shale and in revealing gas transport mechanisms in shale matrix. In future studies, $K_{a p p}$ based on the real shale sample will be analyzed.

\section{Acknowledgement}

The authors would like to acknowledge the support from SCOPE, UNSW and the LDRD program of LANL. J.W. would like to acknowledge the financial support from the China Scholarship Council (CSC). J.W. also thanks the suggestions from Prof. Andreas Seidel-Morgenstern, Max Planck Institute for Dynamics of Complex Technical Systems, Magdeburg. L.C. would also like to acknowledge the support from National Nature Science Foundation of China (No. 51406145,51136004), and Q.K. would also like to acknowledge the support from a DOE oil \& gas project. 
[1] R. G. Loucks, R. M. Reed, S. C. Ruppel, D. M. Jarvie, Morphology, genesis, and distribution of nanometer-scale pores in siliceous mudstones of the mississippian barnett shale, Journal of sedimentary research 79 (12) (2009) 848-861.

[2] C. H. Sondergeld, K. E. Newsham, J. T. Comisky, M. C. Rice, C. S. Rai, et al., Petrophysical considerations in evaluating and producing shale gas resources, in: SPE Unconventional Gas Conference, Society of Petroleum Engineers, 2010.

[3] F. Javadpour, D. Fisher, M. Unsworth, et al., Nanoscale gas flow in shale gas sediments, Journal of Canadian Petroleum Technology 46 (10).

[4] H. Singh, Nonempirical apparent permeability of shale, Unconventional Resources Technology Conference (URTEC), 2013.

[5] G. Karniadakis, A. Beskok, N. Aluru, Microflows and nanoflows: fundamentals and simulation, Vol. 29, Springer, 2006.

[6] Y.-S. Wu, J. Li, D. Ding, C. Wang, Y. Di, et al., A generalised framework model for the simulation of gas production in unconventional gas reservoirs, SPE Journal 19 (05) (2014) 845-857.

[7] Z.-Z. Li, T. Min, Q. Kang, Y.-L. He, W.-Q. Tao, Investigation of methane adsorption and its effect on gas transport in shale matrix through microscale and mesoscale simulations, International Journal of Heat and Mass Transfer 98 (2016) 675-686.

[8] T. Wu, D. Zhang, Impact of adsorption on gas transport in nanopores, Scientific Reports 6.

[9] K. Wu, Apparent permeability for gas flow in shale reservoirs coupling effects of gas diffusion and desorption, Unconventional Resources Technology Conference (URTEC), 2014.

[10] K. Wu, X. Li, C. Wang, W. Yu, Z. Chen, Model for surface diffusion of adsorbed gas in nanopores of shale gas reservoirs, Industrial \& Engineering Chemistry Research 54 (12) (2015) 3225-3236.

[11] A. Beskok, G. E. Karniadakis, Report: a model for flows in channels, pipes, and ducts at micro and nano scales, Microscale Thermophysical Engineering 3 (1) (1999) 43-77. 
[12] F. Civan, Effective correlation of apparent gas permeability in tight porous media, Transport in porous media 82 (2) (2010) 375-384.

[13] F. A. Florence, J. Rushing, K. E. Newsham, T. A. Blasingame, et al., Improved permeability prediction relations for low permeability sands, in: Rocky Mountain Oil \& Gas Technology Symposium, Society of Petroleum Engineers, 2007.

[14] X. Xiong, D. Devegowda, M. Villazon, G. German, R. F. Sigal, F. Civan, et al., A fully-coupled free and adsorptive phase transport model for shale gas reservoirs including non-darcy flow effects, in: SPE Annual Technical Conference and Exhibition, Society of Petroleum Engineers, 2012 .

[15] C. Freeman, G. Moridis, T. Blasingame, A numerical study of microscale flow behavior in tight gas and shale gas reservoir systems, Transport in porous media 90 (1) (2011) 253-268.

[16] M. E. Curtis, R. J. Ambrose, C. H. Sondergeld, et al., Structural characterization of gas shales on the micro-and nano-scales, in: Canadian Unconventional Resources and International Petroleum Conference, Society of Petroleum Engineers, 2010.

[17] L. Chen, Q. Kang, Y. Mu, Y. He, W. Tao, A critical review of the pseudopotential multiphase lattice boltzmann model: Methods and applications, International Journal of Heat and Mass Transer 76 (2014) 210-236.

[18] X. Nie, G. D. Doolen, S. Chen, Lattice-boltzmann simulations of fluid flows in mems, Journal of Statistical Physics 107 (1-2) (2002) 279-289.

[19] Z. Guo, B. Shi, T. Zhao, C. Zheng, Discrete effects on boundary conditions for the lattice boltzmann equation in simulating microscale gas flows, Physical Review E 76 (5) (2007) 056704.

[20] L. Chen, L. Zhang, Q. Kang, H. S. Viswanathan, J. Yao, W. Tao, Nanoscale simulation of shale transport properties using the lattice boltzmann method: permeability and diffusivity, Scientific reports 5 . 
[21] J. Ren, P. Guo, Z. Guo, Z. Wang, A lattice boltzmann model for simulating gas flow in kerogen pores, Transport in Porous Media 106 (2) (2015) 285-301.

[22] E. Fathi, Lattice boltzmann method for simulation of shale gas transport in kerogen, SPE Journal 18 (1) (2013) 27-37.

[23] J. Wang, L. Chen, Q. Kang, S. S. Rahman, The lattice boltzmann method for isothermal micro-gaseous flow and its application in shale gas flow: a review, International Journal of Heat and Mass Transfer 95 (2016) 94-108.

[24] L. Chen, Q. Kang, R. Pawar, Y.-L. He, W.-Q. Tao, Pore-scale prediction of transport properties in reconstructed nanostructures of organic matter in shales, Fuel 158 (2015) 650-658.

[25] L. Chen, W. Fang, Q. Kang, J. D. Hyman, H. S. Viswanathan, W.-Q. Tao, Generalized lattice boltzmann model for flow through tight porous media with klinkenberg's effect, Physical Review E 91 (3) (2015) 033004.

[26] Z. Guo, T. Zhao, Lattice boltzmann model for incompressible flows through porous media, Physical Review E 66 (3) (2002) 036304.

[27] L. Chen, Q. Kang, Z. Dai, H. S. Viswanathan, W. Tao, Permeability prediction of shale matrix reconstructed using the elementary building block model, Fuel 160 (2015) 346-356.

[28] R. E. cunningham, R. Willliams, Diffusion in gases and porous media, springer, 1980.

[29] S. K. Bhatia, M. R. Bonilla, D. Nicholson, Molecular transport in nanopores: a theoretical perspective, Physical Chemistry Chemical Physics 13 (34) (2011) 15350-15383.

[30] R. Krishna, Problems and pitfalls in the use of the fick formulation for intraparticle diffusion, Chemical Engineering Science 48 (5) (1993) 845-861.

[31] R. Krishna, J. Wesselingh, The maxwell-stefan approach to mass transfer, Chemical Engineering Science 52 (6) (1997) 861-911. 
[32] E. A. Mason, A. Malinauskas, Gas transport in porous media: the dustygas model, Vol. 17, Elsevire, 1983.

[33] A. Tuchlenski, P. Uchytil, A. Seidel-Morgenstern, An experimental study of combined gas phase and surface diffusion in porous glass, Journal of Membrane Science 140 (2) (1998) 165-184.

[34] M. E. Naraghi, F. Javadpour, A stochastic permeability model for the shale-gas systems, International Journal of Coal Geology 140 (2015) $111-124$.

[35] A. Al Hinai, R. Rezaee, L. Esteban, M. Labani, Comparisons of pore size distribution: A case from the western australian gas shale formations, Journal of Unconventional Oil and Gas Resources 8 (2014) 1-13.

[36] M. Kutílek, L. Jendele, K. P. Panayiotopoulos, The influence of uniaxial compression upon pore size distribution in bi-model soils, Soil and Tillage Research 86 (1) (2006) 27-37.

[37] P. Nithiarasu, K. Seetharamu, T. Sundararajan, Natural convective heat transfer in a fluid saturated variable porosity medium, International Journal of Heat and Mass Transfer 40 (16) (1997) 3955-3967.

[38] J. Gao, H. Xing, Z. Tian, H. Muhlhaus, Lattice boltzmann modeling and evaluation of fluid flow in heterogeneous porous media involving multiple matrix constituents, Computers \& Geosciences 62 (2014) 198-207.

[39] H. Sun, J. Yao, D.-y. Fan, C.-c. Wang, Z.-x. Sun, Gas transport mode criteria in ultra-tight porous media, International Journal of Heat and Mass Transfer 83 (2015) 192-199.

[40] F. Verhaeghe, L.-S. Luo, B. Blanpain, Lattice boltzmann modeling of microchannel flow in slip flow regime, Journal of Computational Physics 228 (1) (2009) 147-157.

[41] F. Javadpour, et al., Nanopores and apparent permeability of gas flow in mudrocks (shale and siltstone), Journal of Canadian Petroleum Technology 48 (08) (2009) 16-21.

[42] A. Sakhaee-Pour, S. Bryant, et al., Gas permeability of shale, SPE Reservoir Evaluation \& Engineering 15 (04) (2012) 401-409. 
[43] D. Do, K. Wang, Dual diffusion and finite mass exchange model for adsorption kinetics in activated carbon, AICHE journal 44 (1) (1998) 68-82.

[44] A. M. Allan, G. Mavko, The effect of adsorption and knudsen diffusion on the steady-state permeability of microporous rocks, Geophysics 78 (2) (2013) D75-D83.

[45] T. Zhang, G. S. Ellis, S. C. Ruppel, K. Milliken, R. Yang, Effect of organic-matter type and thermal maturity on methane adsorption in shale-gas systems, Organic Geochemistry 47 (2012) 120-131.

[46] S. A. Mengal, R. A. Wattenbarger, et al., Accounting for adsorbed gas in shale gas reservoirs, in: SPE Middle East Oil and Gas Show and Conference, Society of Petroleum Engineers, 2011.

[47] A. Boulis, R. Jayakumar, F. Lalehrokh, H. Lawal, et al., Improved methodologies for more accurate shale gas assessments, in: SPE Americas Unconventional Resources Conference, Society of Petroleum Engineers, 2012.

[48] M. D. Zuber, J. R. Williamson, D. G. Hill, W. K. Sawyer, J. H. Frantz Jr, et al., A comprehensive reservoir evaluation of a shale reservoir-the new albany shale, in: SPE Annual Technical Conference and Exhibition, Society of Petroleum Engineers, 2002.

[49] T. F. Rexer, M. J. Benham, A. C. Aplin, K. M. Thomas, Methane adsorption on shale under simulated geological temperature and pressure conditions, Energy \& Fuels 27 (6) (2013) 3099-3109.

[50] R. Heller, M. Zoback, Adsorption of methane and carbon dioxide on gas shale and pure mineral samples, Journal of Unconventional Oil and Gas Resources 8 (2014) 14-24.

[51] S. R. Etminan, F. Javadpour, B. B. Maini, Z. Chen, Measurement of gas storage processes in shale and of the molecular diffusion coefficient in kerogen, International Journal of Coal Geology 123 (2014) 10-19.

[52] H. Hu, Methane adsorption comparison of different thermal maturity kerogens in shale gas system, Chinese Journal of Geochemistry 33 (4) (2014) 425-430. 
[53] S. M. Kang, E. Fathi, R. J. Ambrose, I. Y. Akkutlu, R. F. Sigal, et al., Carbon dioxide storage capacity of organic-rich shales, Spe Journal 16 (04) (2011) 842-855.

[54] I. Y. Akkutlu, E. Fathi, et al., Multiscale gas transport in shales with local kerogen heterogeneities, SPE Journal 17 (04) (2012) 1-002.

[55] Z. Zhai, X. Wang, X. Jin, L. Sun, J. Li, D. Cao, Adsorption and diffusion of shale gas reservoirs in modeled clay minerals at different geological depths, Energy \& Fuels 28 (12) (2014) 7467-7473.

[56] W. Yuan, Z. Pan, X. Li, Y. Yang, C. Zhao, L. D. Connell, S. Li, J. He, Experimental study and modelling of methane adsorption and diffusion in shale, Fuel 117 (2014) 509-519.

[57] K. Wu, X. Li, C. Guo, C. Wang, Z. Chen, et al., A unified model for gas transfer in nanopores of shale-gas reservoirs: Coupling pore diffusion and surface diffusion, SPE Journal.

[58] M. Okazaki, H. Tamon, R. Toei, Interpretation of surface flow phenomenon of adsorbed gases by hopping model, AIChE Journal 27 (2) (1981) 262-270.

[59] Y. Horiguchi, R. Hudgins, P. Silveston, Effect of surface heterogeneity on surface diffusion in microporous solids, The Canadian Journal of Chemical Engineering 49 (1) (1971) 76-87.

[60] H. Ramanan, S. M. Auerbach, Modeling jump diffusion in zeolites: I. principles and methods, in: Fluid Transport in Nanoporous Materials, Springer, 2006, pp. 93-125.

[61] R. S. Middleton, J. W. Carey, R. P. Currier, J. D. Hyman, Q. Kang, S. Karra, J. Jiménez-Martínez, M. L. Porter, H. S. Viswanathan, Shale gas and non-aqueous fracturing fluids: Opportunities and challenges for supercritical co 2, Applied Energy 147 (2015) 500-509.

[62] H. Darabi, A. Ettehad, F. Javadpour, K. Sepehrnoori, Gas flow in ultratight shale strata, Journal of Fluid Mechanics 710 (2012) 641-658.

[63] Y.-S. Wu, J. Li, D. Ding, C. Wang, Y. Di, et al., A generalized framework model for the simulation of gas production in unconventional gas reservoirs, SPE Journal 19 (05) (2014) 845-857. 
${ }_{743}^{6}$ [64] E. B. Arkilic, M. A. Schmidt, K. S. Breuer, Gaseous slip flow in long 744 microchannels, Microelectromechanical Systems, Journal of 6 (2) (1997) $745 \quad 167-178$. 